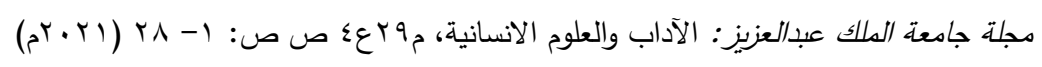

DOI:10.4197/Art.29-4.1

\title{
المناخ الأسري وعلاقته بالاتجاه نحو التطرف الفكري والانتماء الوطني لدى عينة من طالبات جامعة الملك عبد العزيز بمدينة جدة
}

\author{
الباحث الرئيسي د. هدى عاصم خليفة

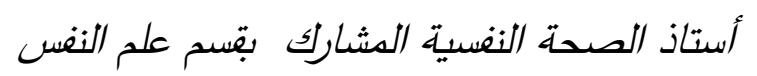 \\ كلية الآداب والعلوم الانسانية -جامعة الملك عبد العزيز \\ الباحث المشارك د. دأميرة عبد الرحمن الزين

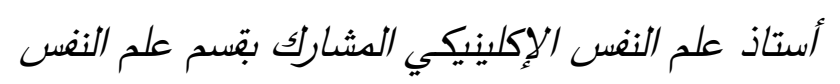

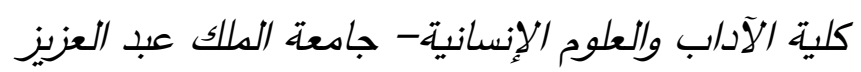

مستخلص. هدفت الدراسة إلى التعرف على العلاقة بين المناخ الأسري و الاتجاه نحو التطرف الفكري و الانتماء

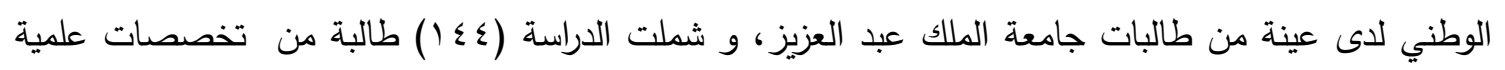

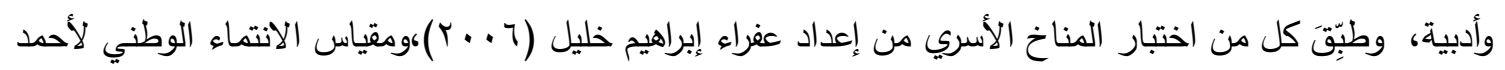

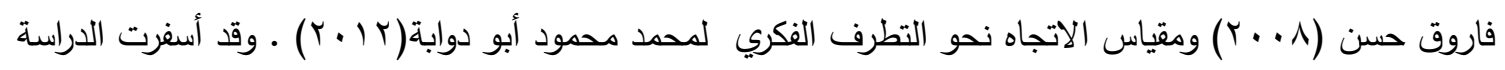

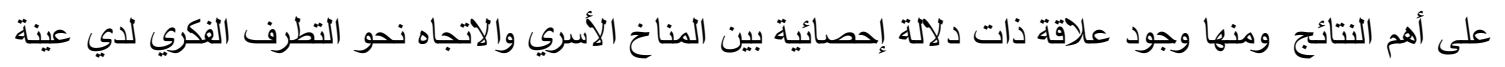

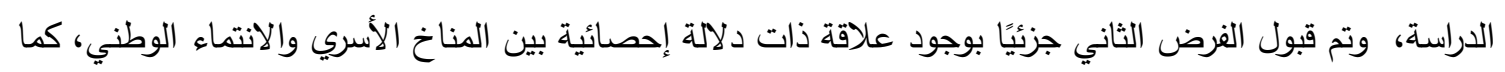

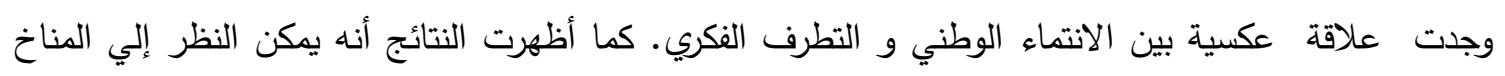

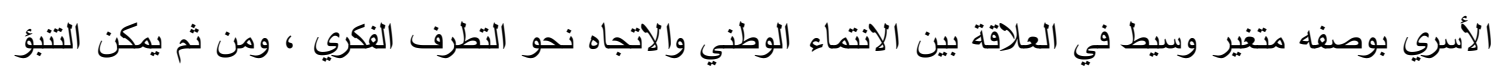

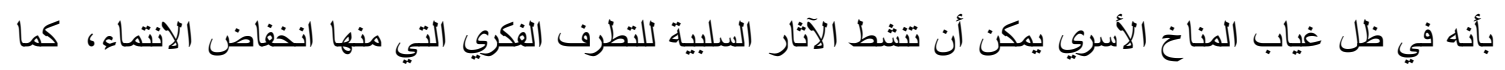

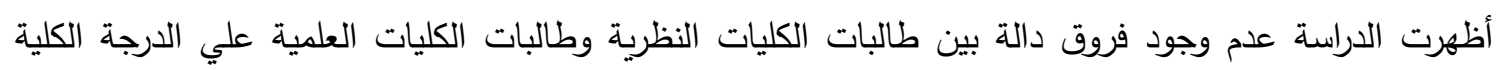

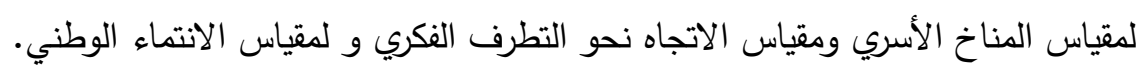

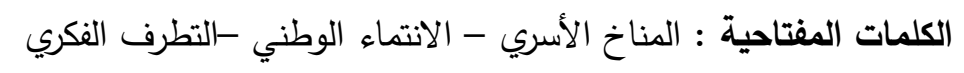

المهمة المتفاعلة في البناء الاجتماعي، فهي تعتبر المقدمة:

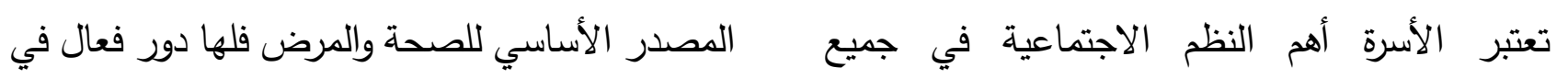

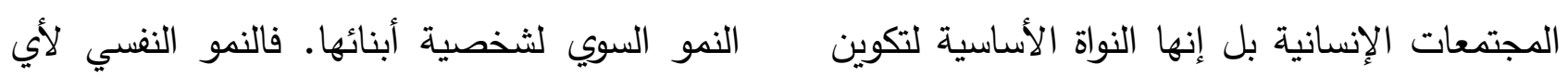
أي مجتمع إنساني، وتقوم الأسرة بالعديد من الوظائف شخص ينتج عن منظومة الأسرة التي ينتمي إليها. 
بانتمائهح الوطني وذلك من خلال الانفتاح على الثقافات الاخرى لاكتساب المعرفة التي تقلص من

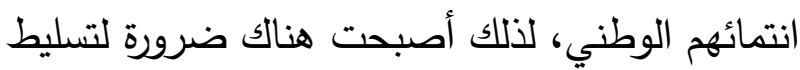
الضوء على بعض الموضوعات كموضوع البحث الحالي. - مثكاء مشكلة الدراسة:

يُحدث المناخ الأسري تغيرات جوهرية في طبيعة علاقاتتا الأسرية وما ويترتب على ذلك من حدوث تغير جوهري في جوانب الشخصية لدى أبنائنا وفي تفاعلهم مع الآخرين وفي دورهم الاجتماعي وانتمائهم الوطني. وفي ظل التحولات والتغيرات التي تهدد انتماءنا الوطني قد يتولد لدى أبنائنا نوع من التطرف الفكري بكل مظاهره وأشكاله .وقد لاحظت الباحثتان من خلال اطلاعهم على بعض البحوث والدراسات

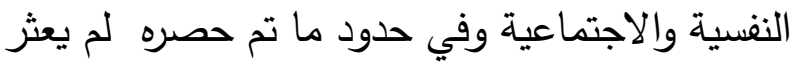
على دراسة نفسية واحدة تعلن أن هدفها هو دراسة كل

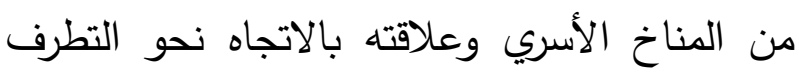
الفكري و الانتماء الوطني لدى عينة من طالبات

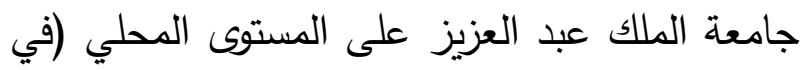
حدود علم الباحثتين ) ولكن وجدا دراسات تناولت كل من متغيرات الدراسة كل على حدة ، فمثلا توجد دراسات تتاولت المناخ الأسري في علاقته بمتغيرات

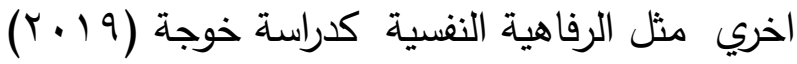

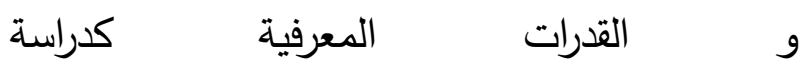
(Dandagal\&Yarriswami,2017) كدراسة قمر (V ا •rم) ، أما الدراسات التي تتاولت
فليس هناك خلاف على أن الأسرة هي أكثر الجماعات

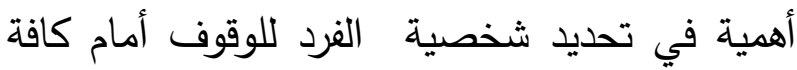
التحديات والصراعات الفكرية بين الافراد والمجتمعات وكافة مظاهر الحياة المدنية، مما جعل متغيرات مثل المناخ الأسري والتطرف الفكري والاتتماء الوطني من أهم الموضوعات التي تساعدنا في فهم التفاعل القائم بين الفرد و الإطار الحضاري الذي يعيش فيه، فمع لهي تعقد الحياة الحديثة والتطور الهائل السريع أصبح الإنسان يواجه العديد من المواقف التي تهدد حياته ومستقبله وتزيد من تطرفه تجاه كثير من الأشياء

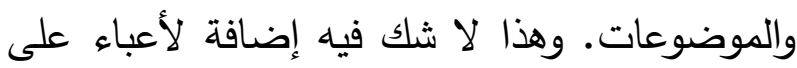
دور الاسرة التي تلعب دورا هاما في تشكيل قيم واتجاهات وانتماءات أبنائها الوطنية ،الذين يشكلون قادة المستقبل. و لذلك تهتم الدول في شتى أنحاء العالم وفي

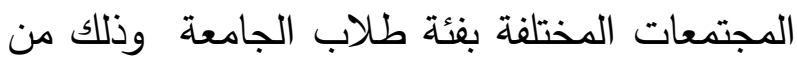
خلا فلسفات وأفكار ترتكز في المقام الأول على ولى بعلى

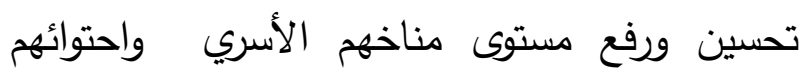
وتوفير السبل الإيجابية والمواتية لإثشباع حاجاتهم وتحقيق مطالبهم وفتح قنوات الحوار معهم لمناقشة مشكلاتهم ومحاولة إيجاد حلول من خلال تتمية

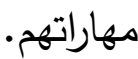
إن التأثيرات التي تحملها السياسات الخارجية تخلق نوعا من التطرف له انعكاساته وتأثيراته على البنية المعرفية للأفراد وما يحملون من اتجاهات وأفكار لاعقلانية في بعض الأحيان تضعف من شعورهم 
ع- هل يتغير حجم الارتباط لدى أفراد عينة الدراسة بين الانتماء الوطني والاتجاه نحو التطرف الفكري بعد العزل الإحصائي للمناخ الأسري؟

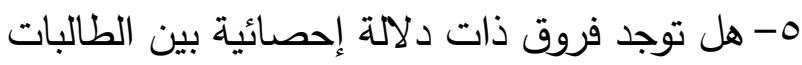

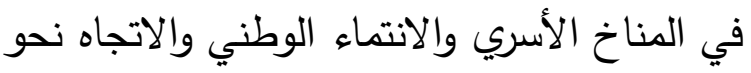

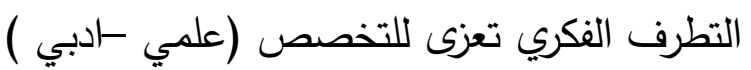
أهداف الدراسة :تهدف الدراسة إلى :-

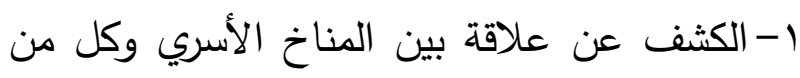
الاتجاه نحو التطرف الفكري والانتماء الوطني لاى الاع عينة الدراسة . ع الهو r- الكشف عن العلاقة بين كل من المناخ الأسري والتطرف الفكري والانتماء الوطني لاى عينة الدراسة . r- الكثف عما إذا كانت توجد فروق دالة احصائيًا

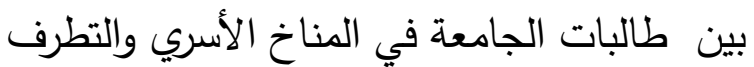
الفكري والانتماء الوطني تعزى لمتغير التخصص لهص لهصي

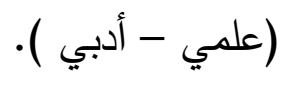

أهمية الدراسة :- اعلئية أ- الأهمية النظرية :- الهية -تكمن أهمية الدراسة في كونها الدراسة المحلية العربية

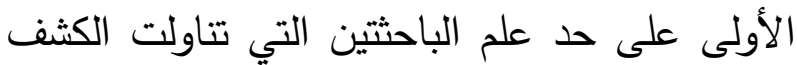

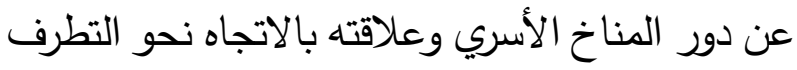
الفكري والانتماء الوطني للى عينة من طالبات
التطرف الفكري في علاقته بمتغيرات أخرى مثل

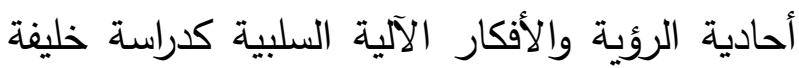

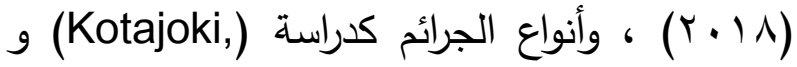

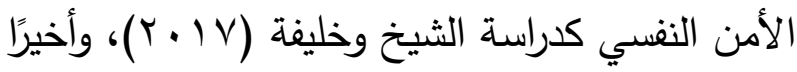
الدراسات التي تتاولت الانتماء الوطني في علاقته بمتغيرات أخرى مثل المسئولية الاجتماعية كدراسة طلب و سليمان (19 (Y. و) و دور الجامعة في تتمية قيم المواطنة كدراسة علي(Y V V Y)، وتنمية الانتماء الوطني كدراسة الأميري( ( ا • ץ). وبناء على ما سبق يمكن تحديد مشكلة الدراسة في التساؤل الرئيسي التالي : التساء ما علاقة المناخ الأسري بكل من؛ الاتجاه نحولئ التطرف الفكري والانتماء الوطني للى عينة من طالبات جامعة الملك عبد العزيز ؟ ويتفرع من هذا التساؤل التساؤلات الفرعية التالية :1- هل توجد علاقة ارتباطية ذات دلالة إحصائية بين

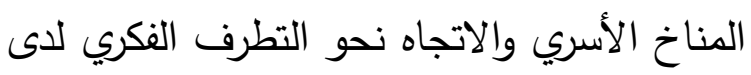

عينة الدراسة ؟

r- هل توجد علاقة ارتباطية ذات دلالة إحصائية بين

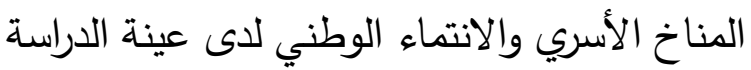
r- هل توجد علاقة ارتباطية ذات دلالة إحصائية بين الاتجاه نحو التطرف الفكري والانتماء الوطني لدى

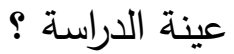

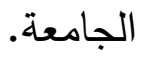


-كما ترجع أهمية الدراسة إلى أنها ركزت على مرحلة عينة من طالبات جامعة الملك عبد العزيز بمدينة الثباب التي يمثلها طلاب الجامعة و تعد أكثر جدة.

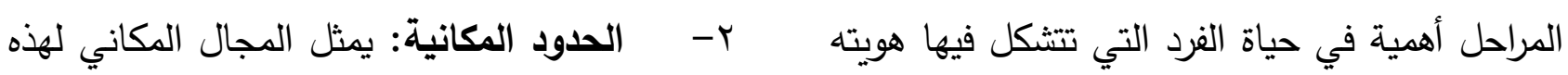

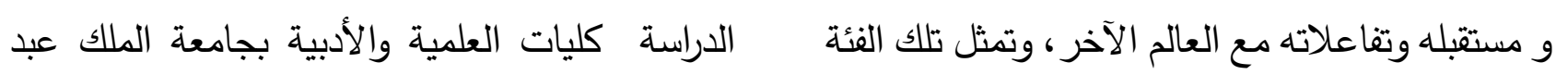
الشريحة الأكبر في المجتمع السعودي المعرضة أكثر العزيز بمدينة جدة.

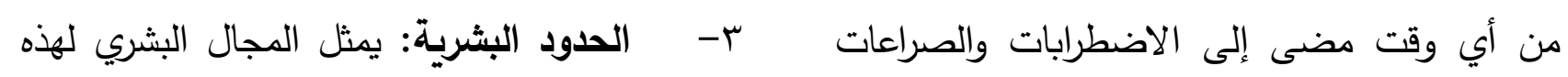

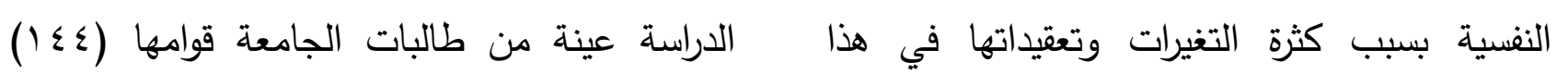

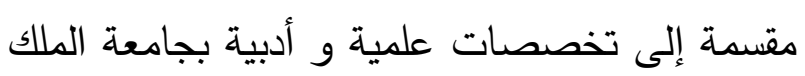

$$
\text { عبد العزيز بمدينة جدة. }
$$

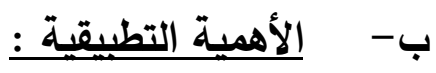

- تتمثل بتوفير قدر مناسب من البيانات والمعلومات ع - الحدود الزمنية: استغرق استكمال الدراسة

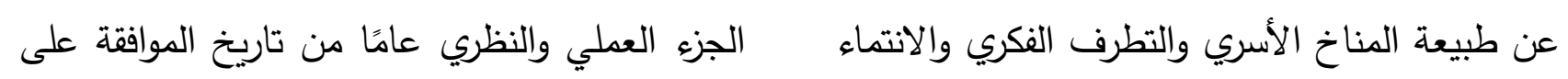
الوطني، ومن ثم تزويد مؤسسات المملكة التربوية الدراسة.

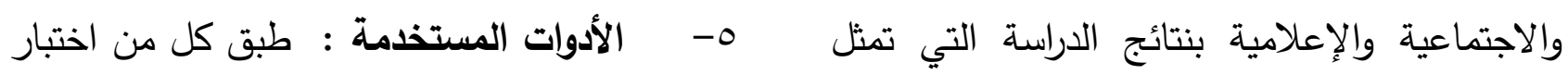

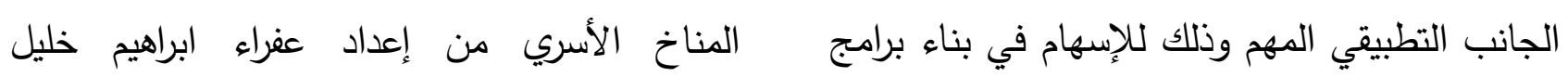

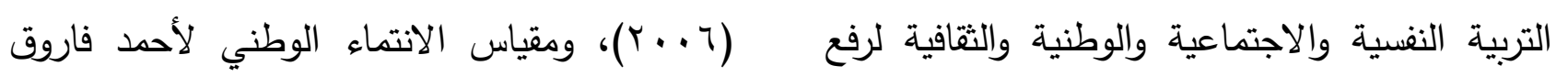

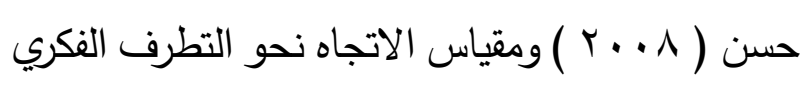

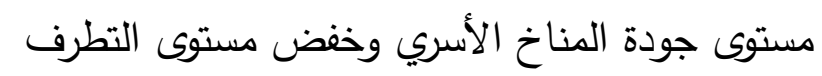
الفكري من خلال تتمية الانتماء الوطني لطلاب الطني

Y- الأساليب الإحصائية المستخدمة :

للتحقق من فروض الدراسة أجريت التحليلات الإحصائية الآتية: - المتوسط الحسابي و الانحراف المعياري.

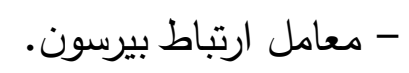
- اختبار ت لعينتين مستقلتين.

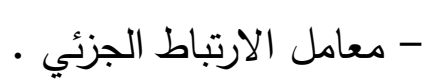

-ومن جانب آخر تحاول الدراسة الكثف عن سلبيات التطرف الفكري وأثر مستوى المناخ الاسري غير التران التشن

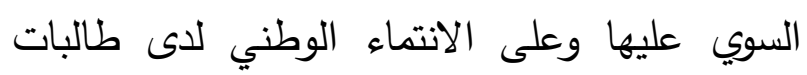
الجامعة . حدود الاراسة :

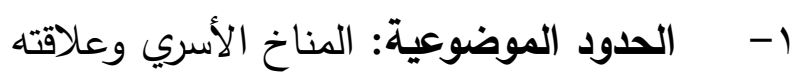
بالاتجاه نحو التطرف الفكري والانتماء الوطني للى الدي وعلي 
الإيجابية: مثل ارتفاع مستوى الإدراك الاجتماعي

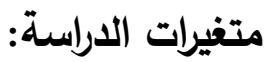
لديهم، وتحسين مستوى تقدير الذات، ورفع مستوى تحتوى الدراسة على عدد من المتغيرات نتناولها فيما

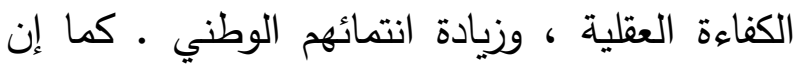
أساليب المعاملة الوالدية الإيجابية تحمي أبنائنا من

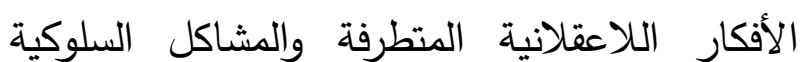
الأخرى(Cleveland et al, 2005).

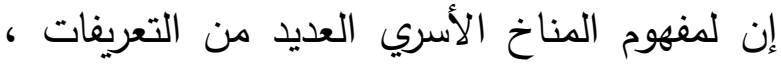

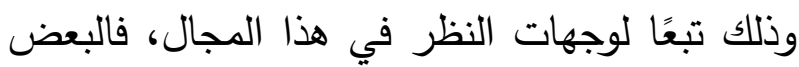
قصر تعريف المناخ الأسري على العلاقات بين أفراد الأسرة، في مقابل البعض الذي توسع في التعريف في مفاهيم عامة غير محددة ، فقد عرفه كفافي (1999 (Y ) بأنه: "الجو الذي يسود الأسرة استتادًا لطبيعة العلاقات الإنسانية والاجتماعية التي تربط

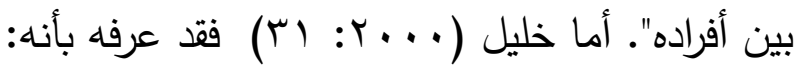
"الطابع العام للحياة الأسرية الذي يتضدن الأمن

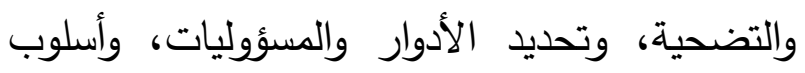

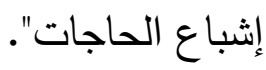
وتتبنى الباحثتان التعريف الإجرائي للمناخ الأسري

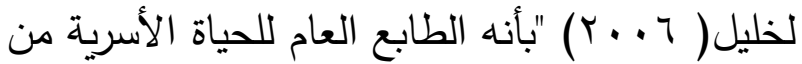
حيث توفر الأمان والتعاون والتضحية ووضوح الأدوار

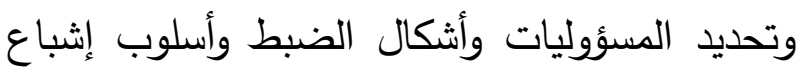

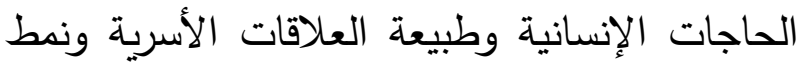
الحياة الروحية والدينية والخلقية التي تسود الأسرة،

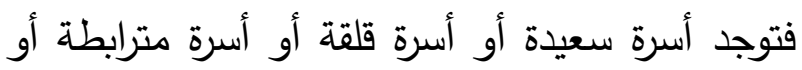

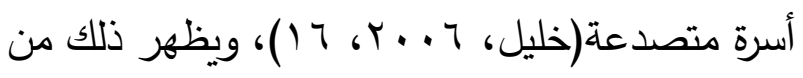
خلال درجة الطالبة على مقياس المناخ الأسري

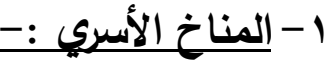 \\ يلي :}

أجمع علماء النفس على أهمية الأسرة و تأثيرها الرئيسي في عملية النمو الإنساني للأبناء، فالأجواء التي تسود الأسرة من أهم العوامل التي تؤثر في سلوك لإكي

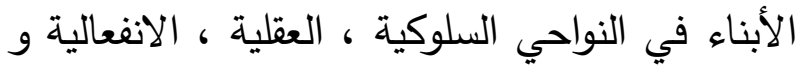
الأخلاقية، فالأسرة هي الوحدة الأساسية والرئيسية الأولى المسؤولة عن تتشئة الأبناء وإعدادهم لمواجهة الحياة بجوانبها المختلفة، فالاستقرار الذي يعيش فيه الأبناء ومدى توافر الأمن والطمأنينة ضدن هذا المناخ هو ما يسهم في تحقيق التوافق النفسي والتكيف

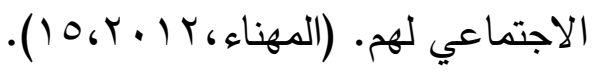
ولا توجد مؤسسة من المؤسسات أو الهيئات التي تستطيع أن تلعب الدور الذي تلعبه الأسرة في حياة

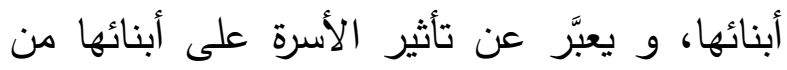
خلال المناخ الذي يسوده، الذي اصطُح على تسميته

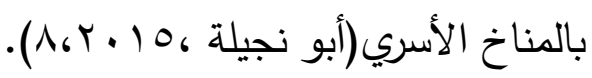

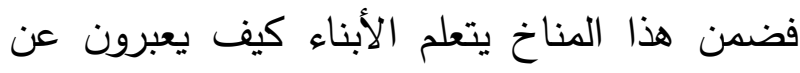
مشاعرهم، وكيف يتعاملون مع المواقف والمشكلات التي تواجهه، فالمناخ العام للأسرة يعد الركيزة

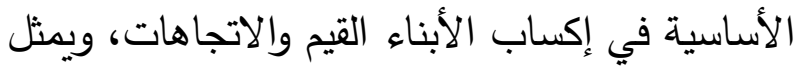
وحدة اجتماعية تربوية تعليمية متكاملة متفاعلة بين مختلف جميع عناصره (أبو نجيلة ، 0 ـ ب ب). إن دعم

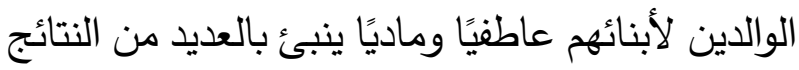


ويتهمهم بالكفر ، ويستخدم معهم أساليب العنف والإرهاب بحجة الجهاد في سبيل الله. وتتبنى الباحثتان التعريف الإجرائي لأبو دوابة

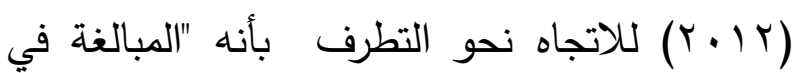
التمسك فكرًا او سلوكًا بمجموعة من الأفكار (دينية سياسية -|قتصادية -أدبية - فنية ) غير مألوفة والخارجة عن معايير المجتمع وسعيه لفرضها على الآخرين بشتى الوسائل وفي شتى مجالات الحياة بدرجة مبالغ فيها من الغلو والتشدد والتعصب" ويقاس بالدرجة الكلية التي تحصل عليها الطالبة المستجيبة وفق إجاباتها لفقرات مقياس الاتجاه نحو التطرف

$$
\begin{aligned}
& \text { الفكري إعداد محمد أبو دوابة(Y I • Y). } \\
& \text { ب- الانتماء الوطني :- أس }
\end{aligned}
$$

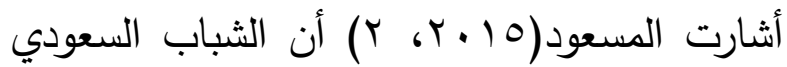
يمر بظروف قاسية فرضت عليهح نتيجة لما يمر به في الآونة الأخيرة كثيرًا من المتغيرات الاجتماعية والإقتصادية والسياسية، التي من أبرز مؤشراتها التضخم السكاني، والبطالة، وعدم التتاسب بين الزيادة في الدخل وزيادة غلاء المعيشة، وغياب دور الأسرة في بناء شخصية الفرد، والابتعاد عن العقيدة السوية ، وافتقاد الأمن الثقافي، وطغيان المادة، وثورة المعلومات، وسرعة الاتصالات والتقدم العلمي، ونتيجة لهذه الانعكاسات مجتمعة كان الأثر بشكل مباشر في اتجاهات الشباب فكريًا وسلوكيًا، ووجد الثباب نفسه محاصرًا بالأفكار الهدامة، ما أدى إلى في عدم الشعور بالاستقرار والقلق وعدم وضوح الرؤية، و
المستخدم في الدراسة من إعداد عغراء ابراهيم خليل

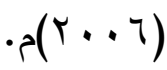
r - التطرف الفكري : أب إن التطرف ظاهرة عالمية لم يحتكرها مجتمع دون آخر، فالمجتمع السعودي كمثل بقية المجتمعات الأخرى يؤثر ويتأثر بما يحيط به من عوامل داخلية وخارجية وأن بروز ظاهرة التطرف فكريا كسلوك يصدر من الثباب الذي يعانى الأفكار الخاطئة والإدراك الخاطئ، ويتبنى قناعات غير منطقية

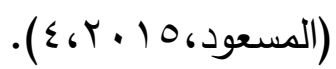

للتطرف الفكري آثار مدمرة على الأمن الوطني والفكري والعقائدي والسياسي والاقتصادي والمجتمعي للدول العربية ، ومن أخطر آثاره الفكر المنحرف والمتطرف مثل تكفير الآخرين واستباحة دمائهم وأموالهم (الصبوة ، ب ا • r). ويعتبر التطرف الفكري اضطرابًا في مستوى التفكير ومحتواه لدى الأفراد والجماعات نحو الأشياء والأشخاص كما يعد هذا التطرف مع الغلو مظهرًا من مظاهر الانحراف عن السواء ويترتب على هذا النوع من التفكير سوء الظن بالآخرين والحكم السلبي المسبق

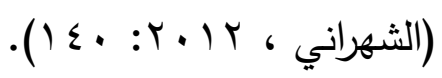
كما يعرفه الشمري (T ( ا ب) بأنه حالة من التعصب في الرأي والخروج عن الحد الاعتدال بتعاليم الدين والمغالاة في تنفيذ أوامر الله ونواهيه، فهي حالة من جمود تفكير الشخص ، فلا يعترف بآراء الآخرين 
حدود ما تم حصره ) ربطت بين أحد المتغيرات

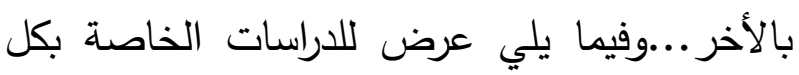
متغير في علاقته بمتغيرات أخرى وفقًا للترتيب الزمني

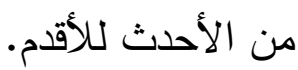
أولًا : دراسات تناولت بالمناخ لألمُ الأسري:

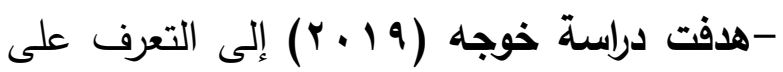
دور الحصانة النفسية كمتغير وسيط في العلاقة بين المناخ الأسري والرفاهية النفسية إضافة إلى التعرف

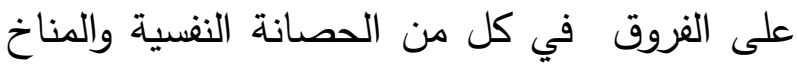
الأسري و الرفاهية النفية وفقًا لمتغيري (المرحلة الدراسية - الحالة الاجتماعية للوالدين)، وذلك على العى عينة من المراهقات بمدينة جدة وبلغت العينة الكلية (r.r) طالبة من المرحلة المتوسطة والثانوية، واستخدمت الباحثة مقياس الحصانة النفسية من إعداد

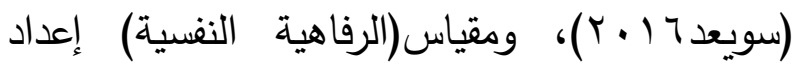
كارول رايف (Carol Ryff,2007) ترجمة: الكثكي (قيد النشر) ومقياس المناخ الأسري من إعداد

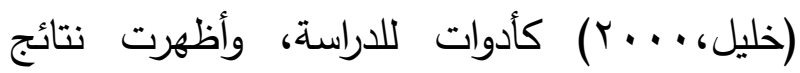
الدراسة وجود علاقة ارتباطية طردية ذات دلالة إحصائية بين الحصانة النفسية وكل من المناخ الأسري والرفاهية النفسية، ووجود علاقة ارتباطية

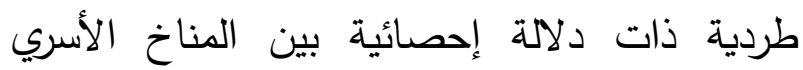
والرفاهية النفسية، وجود مسارات دالة إحصائيا للحصانة النفسية كمتغير وسيط في العلاقة بين المناخ الأسري والرفاهية النفسية، وجدت فروق دالة إحصائيًا في كل من الحصانة النفسية والمناخ الأسري وفقًا
عدم إيجاد حلول لمشكلاتهم وفقدان الشعور بأهيتهم في الحياة، ما أسهر في شيوع ظاهرة التطرف الناتج

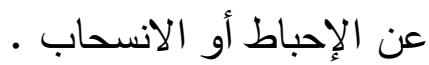

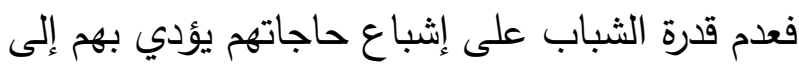
فقدان الانتماء لمجتمعه ووطنهم ، فيسهل وقوعهم فريسة للأفكار السلبية والسيئة وقد يدفعه ذلك إلى فلى فلى فلى

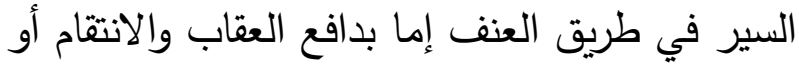

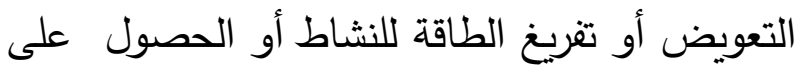
العائد المادي أو المعنوي عندما يقترب من سلوكيات مرفوضة تتعارض مع قيم ومبادئ يتصدى له المجتمع، أو يقوم الفرد بالبحث عن أماكن أخرى لأن لإشباع حاجاته كالانتماء إلى جماعات متطرفة، ومن

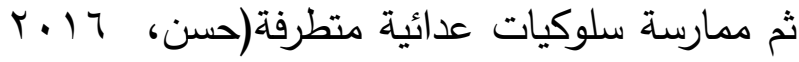
.$(\varepsilon:$ وتتبنى الباحثتان التعريف الإجرائي للانتماء الوطني بأنه " شعور الفرد بمكانته وقيمته داخل الوطن وإحساسه بالرضا والاعتزاز بالوطن وتقبله لقيم ومعايير الوطن ومشاركته الإيجابية وتعاونه وتحمل المسئولية وتضحيته من أجله والمحافظة على ممتلكاته العامة" و يقاس بالدرجة الكلية التي تحصل عليها المستجيبة وفق إجاباتها على فقرات مقياس الانتماء الوطني من

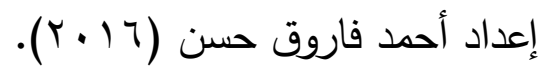
الاراسات السابقة: من خلال ما اتيح للباحثين الاطلاع عليه من دراسات

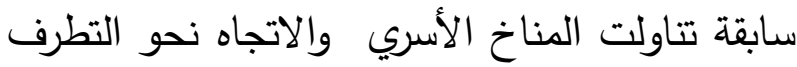
الفكري والانتماء الوطني لم يجدا دراسة واحدة( في ولئه 
المناخ الأسري والصحة النفسية وانخفاض مستوى

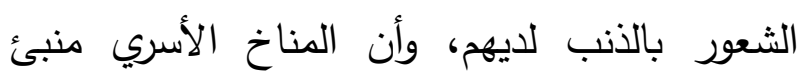
بالصحة النفسية لدى أفراد عينة الدراسة.

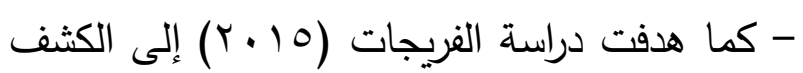
عن العلاقة بين المناخ الأسري وبعض مظاهر الصحة النفسية لاى مجموعة من طلبة وطالبات كلية

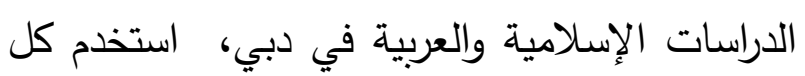
من مقياس المناخ الأسري ومقياس الصحة النفسية.

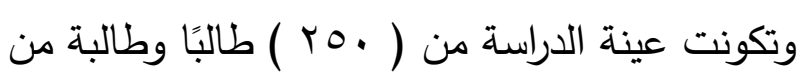
طلاب وطالبات الفرق الدراسية الأولى والثانية والثالثة. وانتهت النتائج إلى وجود إرتباطات سالبة دالة إحصائيًا بين أبعاد المناخ الأسري والمقاييس الفرعية للاستبانة ميدل سكس مما يدل على وجود علاقة

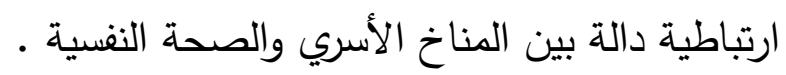

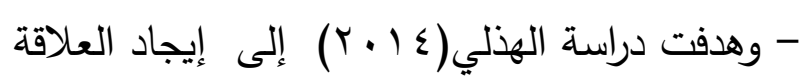
بين المناخ الأسري وانعكاسه على النضج الاجتماعي

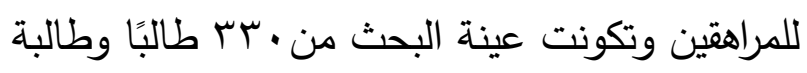
في مرحلة المراهقة من مستويات اجتماعية واقتصادية مختلفة وأستخدمت الباحثة إستمارة البيانات الأولية

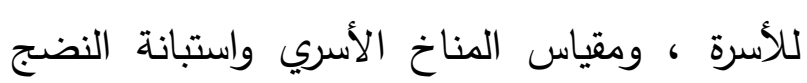
الاجتماعي وتوصلت الباحثة إلى مجموعة من النتائج هي : وجود ارتباط طردي بين محاور استبانة المناخ الأسري ومحاور استبانة النضج الاجتماعي، كلما زاد

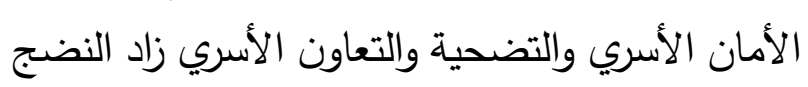

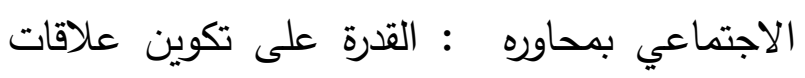
اجتماعية - القدرة على تحمل المسؤولية - القدرة على لعى على على
للمرحلة الدراسية لصالح المرحلة المتوسطة، ولم توجد فروق دالة إحصائًا في كل من الحصانة النفسية والمناخ الأسري وفقًا للحالة الاجتماعية للوالدين. - هدفت دراسة (Dandagal \&Yarriswami,2017) مقارنة التجارب المدرسية والقدرات المعرفية لطلاب

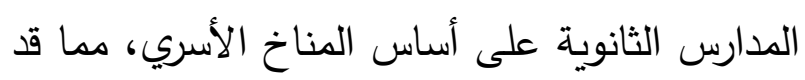

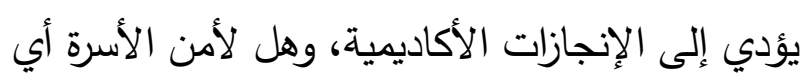

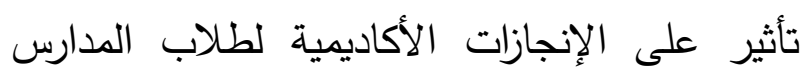
الثانوية؟ يهدف الباحث إلى التحقيق في السبب وراء

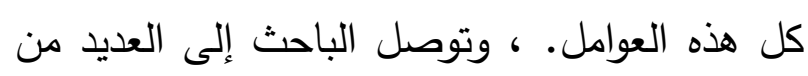
النتائج: تشابه المناخ الأسري لطلاب ولتول وطالبات

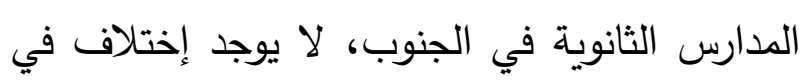

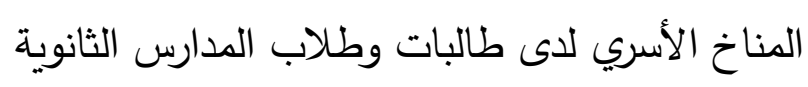

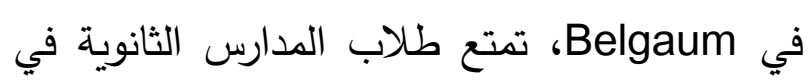

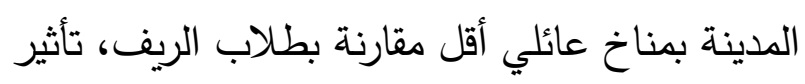
المناخ الأسري الجيد على الطلاب والطالبات بطريقة إيجابية في الإنجاز الأكاديمي.

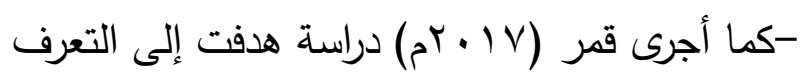
على المناخ الأسري وعلاقته بالصحة النفسية والثعور بالذنب لدى طلبة جامعة نقلا، وتكونت عينة الدراسة من (1.1) طالب، وطور الباحث مقياس المناخ

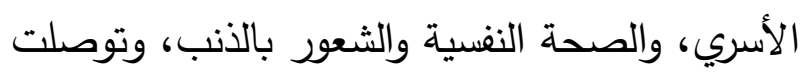

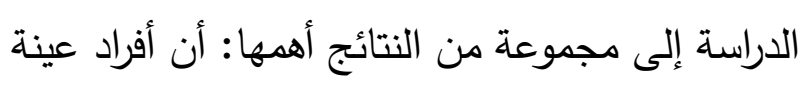

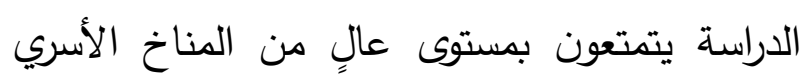

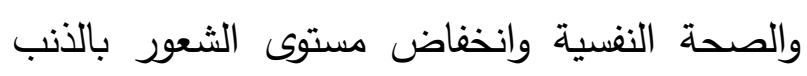
لديهم، ووجود علاقة ذات دلالة إحصائية موجبة بين 
وأُعدَّ مقياس للمناخ الأسري وقد تحققت الباحثة من

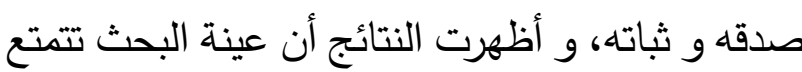
بمناخ أسري جيد لكلا الجنسين و عدم وجود علاقة لهابة

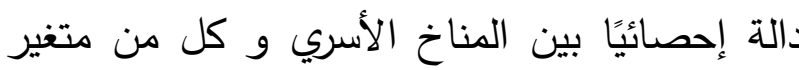

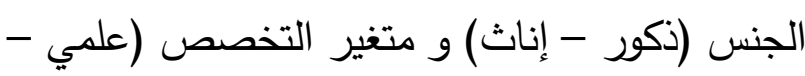
أدبي). - أجرى (Muddry, et al, 2007) دراسة هدفت إلى التعرف على علاقة المناخ الأسري العاطفي

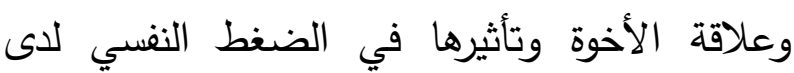
المراهقين، وتكونت عينة الدراسة من (10 (1) طالبًا

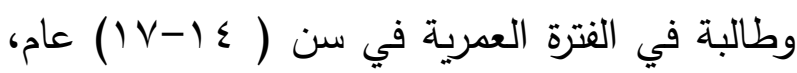
وحدِّد الأشقاء المشاركون والعلاقة بينهم للتنبؤ بتوافقهر وكذلك حددت خصائص الأسرة في التعبير العاطفي وتعرض الطالب للصراع واتفاق الوالدين في التربية،

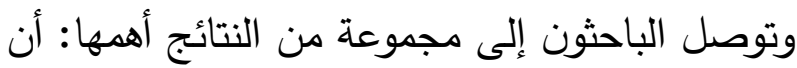
العلاقة الدافئة بين الطالب وإخوته والتعبير العاطفي واتفاق الوالدين في التربية أسهمت بشكل كبير في

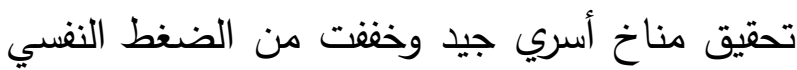
الأني يتعرض له.

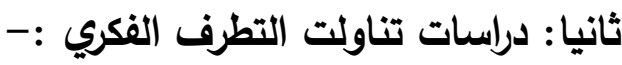
- هدفت دراسة القبساني (19 ـ ب) إلى التعرف على أثر التطرف الأيديولوجي كمنبئ للاتجاه للجريمة لدى الدئي عينة من الثباب السعودي، والتعرف على اتجاهاتهر نحو مظاهر التطرف الإيديولوجي، والكثف عن أكثر مظاهر التطرف انتشارًا، ومستوى التطرف والاتجاه نحو الجريمة لاى عينة الدراسة، واشتملت عينة
تقبل نقد الآخرين - القدرة على اتخاذ القرار - القدرة

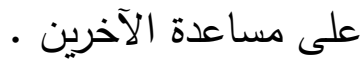
- هدفت دراسة ميرة(Y (Y) التعرف على المناخ الأسري عند طلبة الجامعة والتعرف على الفروق في

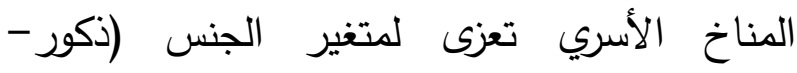
أناث.)والتخصص (علمي-إنساني)والتعرف العلاقة لإنسيري الارتباطية بين المناخ الأسري والتكيف الأكاديمي، وقد

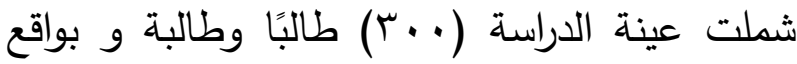

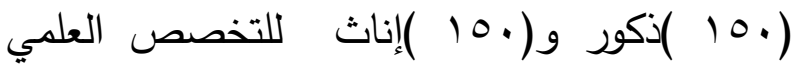
والإنساني اختيروا عشوائيًا. ولتحقيق أهداف البحث

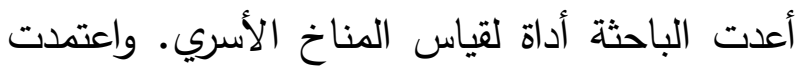

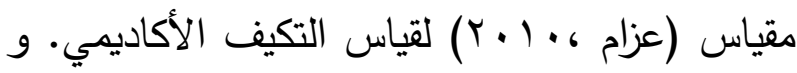

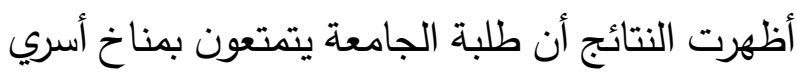
سوي. كما أظهرت النتائج عدم وجود فروق ذات دلالة إحصائية تبعًا لمتغير الجنس في حين ظهرت فروق في المناخ الأسري في التخصص الإنساني. أما في

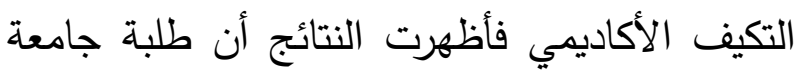
بغداد يتمتعون بتكيف أكاديمي جيد وهذا جاء نتيجة المناخ الأسري السوي الذي يتمتعون به. في حين

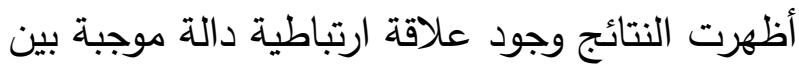
المناخ الأسري والتكيف الأكاديمي.

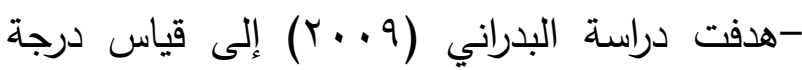
المناخ الأسري لدى عينة من طلبة الجامعة تألفت من لهن (ror) طالبًا و طالبة. و معرفة علاقة المناخ الأسري بمتغير الجنس (ذكور - إناث) و كذلك معرفة علاقة المناخ الأسري بمتغير التخصص (علمي - أدبي). 
-هدفت دراسة (Kotajoki,2018) الكثف عن العلاقة بين التطرف الفكري وأنواع الجرائم المختلفة في

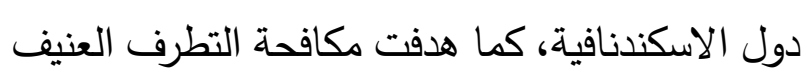
والوقاية منه وقد قام الباحث بمراجعة الخطط التي

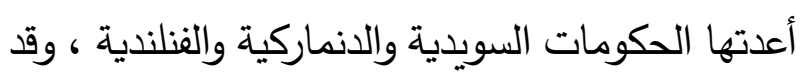

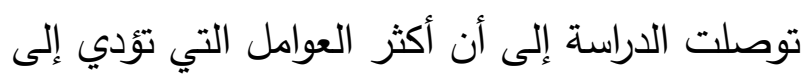
العنف والجرائم كانت شعور المواطنين بعدم المساواة والتمييز العنصري والطبقية ، كما وجدوا أن مرجع الكراهية والعنف هي أيديولوجيات متطرفة .

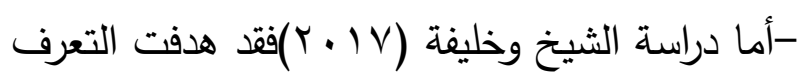
على مدى ممارسة الأنثطة الترويحية ومستوى الأمن النفسي والاتجاه نحو التطرف الفكري لاى عينة من الشباب السعودي والكثف أيضًا عن العلاقة بين كل

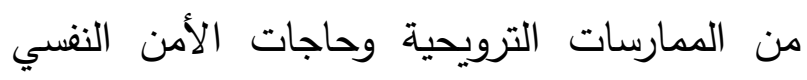
والاتجاه نحو التطرف الفكري ، كما هدفت الدراسة

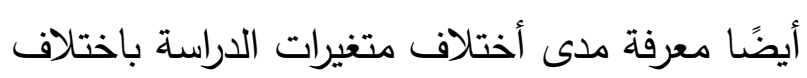
بعض المتغيرات الديموغرافية (الجنس - التخصص) اختئل

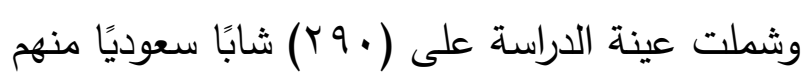

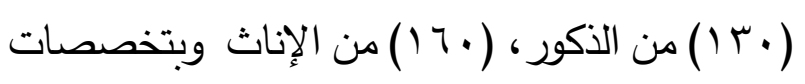

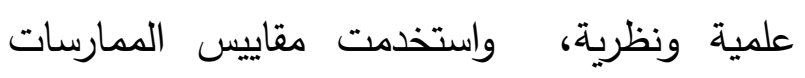

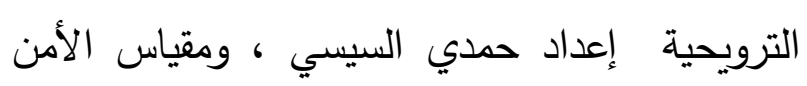

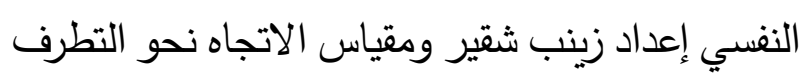

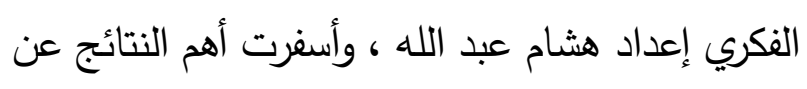
وجود مستوى من التطرف افكري لدى عينة الدراسة،

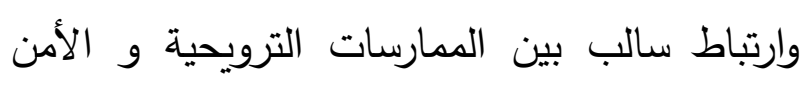
النفسي والاتجاه نحو التطرف الفكري.

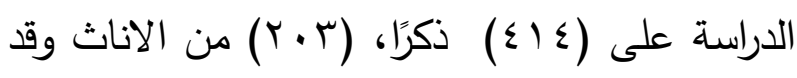
اسفرت الدراسة عن أهم النتائج وهي وجود علاقة دالة التح بين التطرف الفكري والاتجاه نحو الجريمة لدى عينة الدراسة، ووجود مستوى متوسط من التطرف الفكري

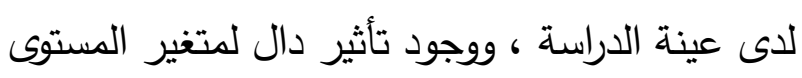

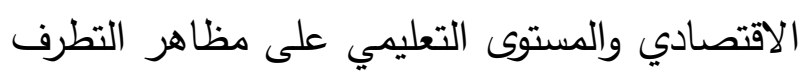
الفكري.

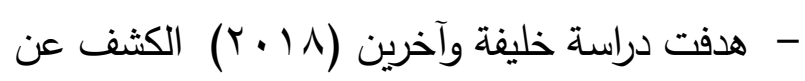
العلاقة بين التطرف الفكري بأحادية الرؤية والأفكار

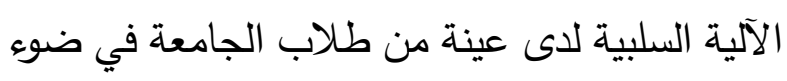
الفروق بين الجنسين والتخصص العملي، وعما إذا كانت توجد فروق بين طلاب الجامعة على متغيرات

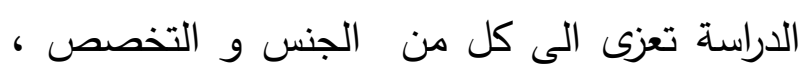

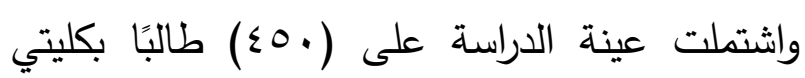
الآداب، والطب، وطبق عليهج كل من مقياس التطرف لإنه

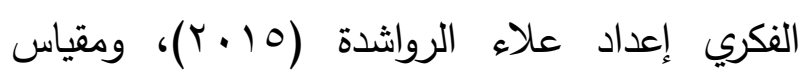

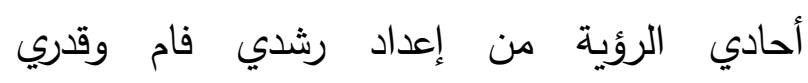
حفني(؟991)، واختبار الآلية السلبية إعداد جيهان

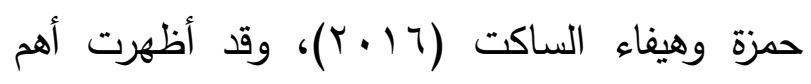
النتائج وجود انتشار لكل من الاتجاه نحو التطرف

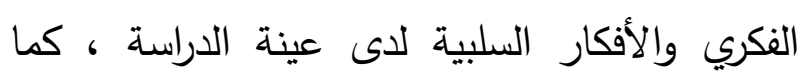

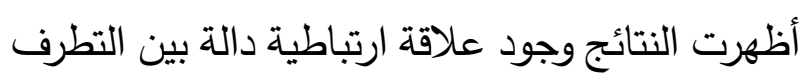
الفكري والأفكار السلبية وأحادية الرؤية لدى عين

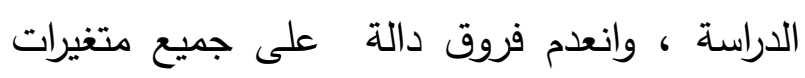

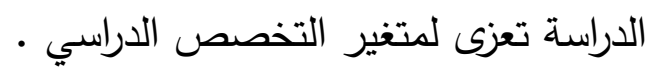


وجهة نظر طلاب الجامعة الأردنية بأنفسهم وأعدت استبانة من (rT) فقرة وذلك على عينة من الطلاب الهن

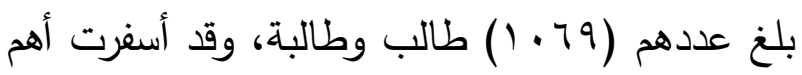
النتائج عن أن للعوامل الاقتصادية والاجتماعية

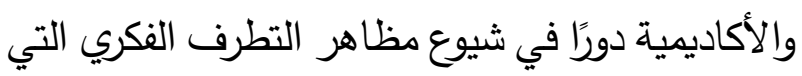
كانت درجة شيوعها لدى طلبة الجامعة الأردنية متوسطة . بينما وجدت دراسة المرعب ( 9. . . ب )التي أجريت على ( 1 1 أ ) طالبًا من طلبة كلية التربية في مدينة حائل أن أعلى درجات التطرف كانت في المجال السياسي، وجاء في المرتبة الثانية المجال الديني يليه الاقتصادي، ثم المجال التربوي، فِالإعلامي، وكانت أقل درجات التطرف في المجال الأُسري. ولا توجد

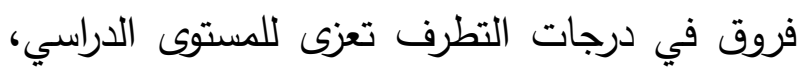
ومعدل الطالب السنوي، وتخصصه. كما لا توجد فروق في أشكال التطرف تعزى إلى الراتب الثهري.

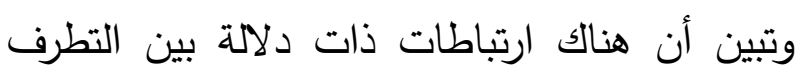

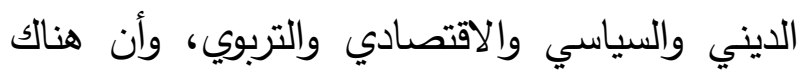
علاقات ذات دلالة إحصائية بين التطرف الاقتصادي

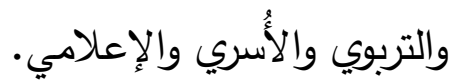

ثالثاً: دراسات تناولت الانتماء الوطني :- هدفت دراسة كل من الحارثي وعطية (19) الكثف عن مستوى من الانتماء الوطني لاى طالبات جامعة طيبة ، كما هدفت الدراسة الكثف عن الفروق بين متوسطات الطالبات على مقياس الانتماء الوطني

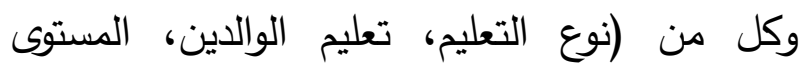

-كما هدفت دراسة الرواشدة (10 • (10) إلى الكثف عن عوامل التطرف الفكري ومظاهره لدى عينة من الثباب الجامعي الأردني وعلاقة التطرف الفكري ببعض المتغيرات الديموغرافية، واشتملت عينة الدراسة على (ع •r) شابٍ جامعٍِ، وأظهرت أهم النتائج وجود بعض مظاهر التطرف الفكري لـى لدى الثباب الأردني ولكنهم يرفضون التطرف الفكري،

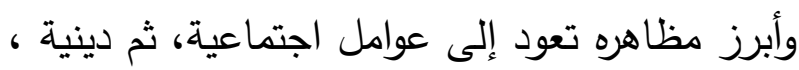
ثم أكاديمية، فأقتصادية، وكان الذكور أعلى من الإناث في الاتجاه نحو التطرف الفكري، ولا توجد فروق في التطرف الفكري تعزى لباقي المتغيرات الديموغرافية

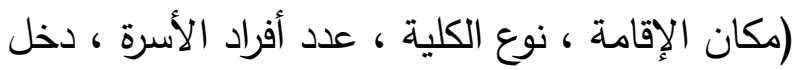

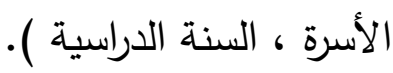

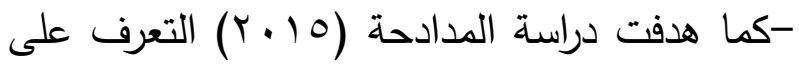
مستوى الضغوط النفسية لدى طلبة جامعة مؤتة، وعلاقتها بكل من التطرف الفكري وتقدير الذات والتحصيل الدراسي ، وطبقت الدراسة على عينة قوامها

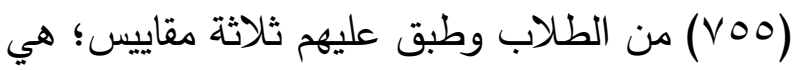
مقياس الضغوط النفسية ومقياس التطرف الفكري ومقياس تقدير الذات، وظهرت أهم النتائج وجود علاقة إيجابية بين الضغوط النفسية والتطرف الفكري، ولم تظهر فروق في التطرف الفكري تعزى للتخصص. وعن مدى شيوع ظاهرة التطرف الفكري لاى طلبة الجامعة كان هدف دراسة كل من بدرانة وفياض وعيروط (11) ب (1) الكثف عن علاقة التطرف الفكري

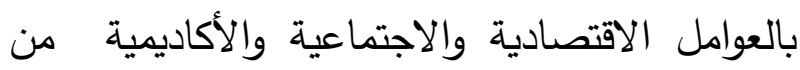


صمم واستخدم الباحثان الأدوات التالية: مقياس المسئولية الاجتماعية، ومقياس قيم المواطنة، وبرنامج إرشادي. وقد توصلت الدراسة إلى عدد من النتائج، منها: وجود ارتباط موجب بين المسئولية الاجتماعية

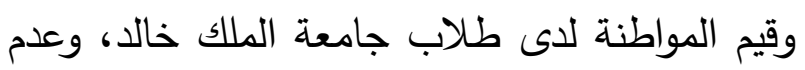
وجود فروق دالة إحصائية بين متوسط درجات الذكور والإناث على مقياسي المسئولية الاجتماعية و قيم المواطنة، وفاعلية البرنامج الإرشادي في تتمية المسئولية الاجتماعية وتعزيز قيم المواطنة لدى أفراد المجموعة التجريبية.

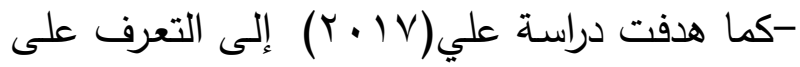
دور الجامعة في تتمية قيم المواطنة والتعرف على درجة تمثل هذه القيم لدى طلابها ووعيهم بأثر لتربه تحديات العولمة في مفهوم وأبعاد المواطنة، ولتحقيق لتحنق

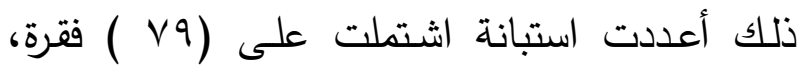

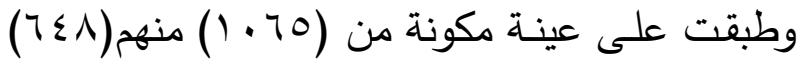

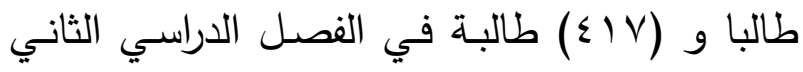

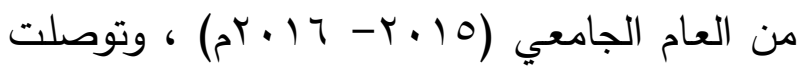
إلى أن الجامعة تسهم بدرجة كبيرة في تتمية قيم المواطنة، وأن درجة تمثل طلبة جامعة أسيوط وسوهاج لقيم المواطنة كانت مرتفعة، كما إنه لا توجد فروق في درجة تمثل الطلبة لقيم المواطنة تعزى لمتغير العمر ونوع الكليات.

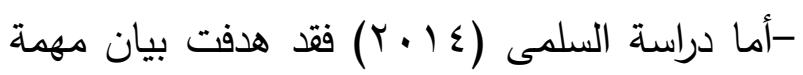
المدرسة الثانوية في مواجهة الإرهاب ودورها في تعزيز الانتماء الوطني لدى الطالبات ، والوقوف على مورهي
الاقتصادي والاجتماعي ) • وقد شملت عينة الدراسة

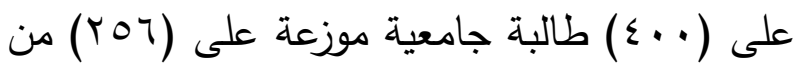
طالبات الكليات النظرية، (ع ـ ( ) من طالبات الكليات العملية ،وطبق مقياس الانتماء الوطني من إعداد

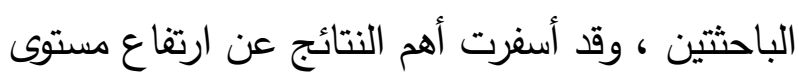
الانتماء الوطني لدى عينة الدراسة ووجود علاقة دالة إحصائيًا بين متوسط درجات عينة الدراسة على مقياس الانتماء ككل وبين متوسط درجاتهم على الأبعاد المكونة له (الولاء للوطن، حماية الوطن، الوطن والمشاركة، الحفاظ على الوطن، الجماعية، الالتزام )، كما وجدت فروق ذات دلالة إحصائية بين متوسطات درجات عينة الدراسة على مقياس الانتماء الوطني تبعا لنوع التعليم لصالح الطالبات بالكليات العملية .

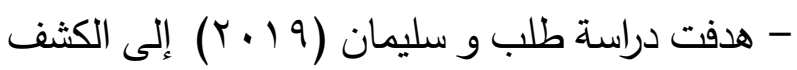
عن طبيعة العلاقة الارتباطية بين المسئولية الاجتماعية وقيم المواطنة لدى عينة من طلاب جامعة الملك خالد، و بحث الفروق بين الذكور والإناث من طلاب الجامعة في المسئولية الاجتماعية، وقيم المواطنة، والكثف عن فاعلية البرنامج الإرشادي في تتمية المسئولية الاجتماعية، وقيم المواطنة لاى عينة الدراسة. وتكونت عينة الدراسة من طلاب وطالبات في مرحلة البكالوريوس بكلية التربية بجامعة الملك

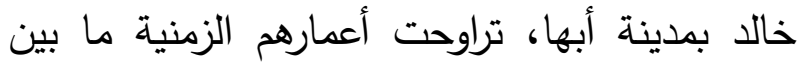
(Y (Y-11) الوصفي، وشبه التجريب، القائم على التصميم التجريبي ذي المجموعتين (تجريبية وضابطة)، وقد 


\section{تعليق عام على الدراسات السابقة :} من خلال الدراسات السابق عرضها التي تلتاولت متغيرات الدراسة نستخلص ما يلي: - إن أغلب الدراسات قد أجريت على طلاب وطالبات

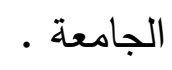
- اختلفت أهداف الدراسات التي تتاولت المتغير نفسه

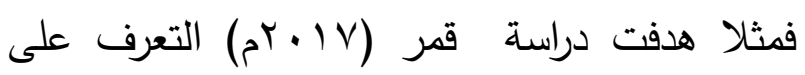
المناخ الأسري وعلاقته بالصحة النفسية والثعور

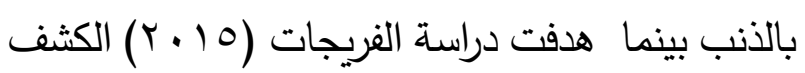
عن العلاقة بين المناخ الأسري وبعض مظاهر دانهر

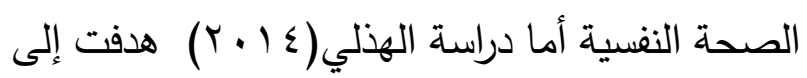
إيجاد العلاقة بين المناخ الأسري وانعكاسه على لمانى

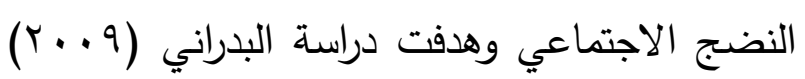

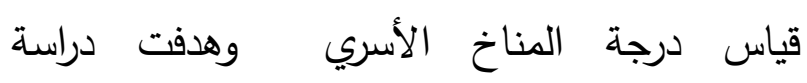
(Muddry, et al, 2007) المناخ الأسري العاطفي وعلاقة الأخوة وتأثيرها في الضغط النفسي - هناك عدم اتفاق إلى حدٍ ما في نتائج الدراسات الخاصة بكل من متغيرات الدراسة و ت تأثرها

$$
\text { بالتخصص العلمي والجنس. }
$$

- أكدت معظم الدراسات الخاصة بمتغير المناخ الخدئ الأسري على أهميته في حماية الثباب من الأثار السلبية المنتشرة في المجتمع وعلى دوره في تعزيز

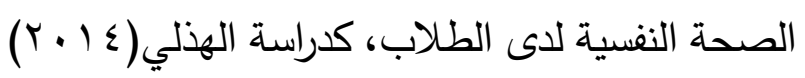

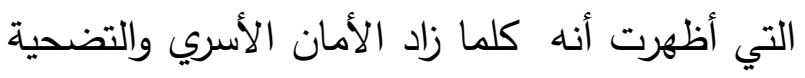

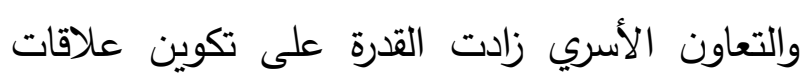

وجهات نظر منسوبات التعليم الثانوي تجاه ظاهرة الإرهاب وتعزيز الانتماء الوطني، وقد أسفرت الدراسة

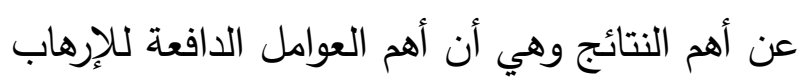

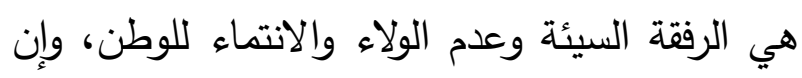
تعزيز الأمن الفكري والانتماء الوطني ليست مسئولية

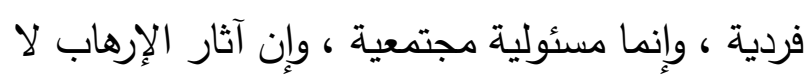
تقتصر على الفرد فقط، وإنما تتجاوز الآثار إلى تهديد الإنها الأمن الوطني بكل دعائمه.

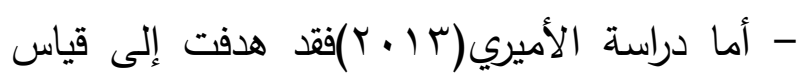
مدى فاعلية البرنامج الإرشادي لتتمية الانتماء الوطني

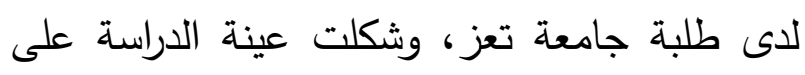

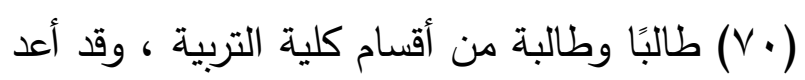

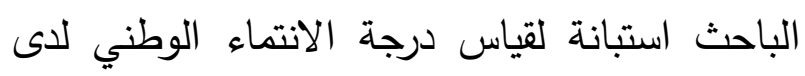

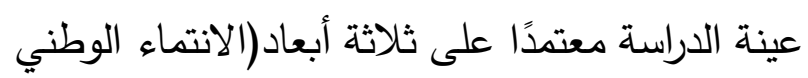

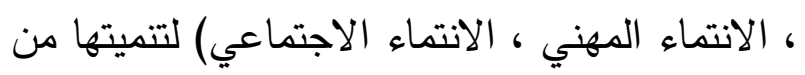

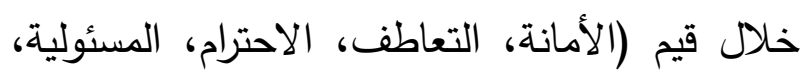

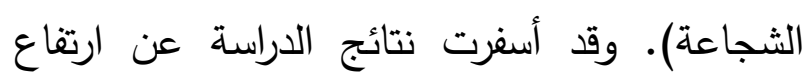

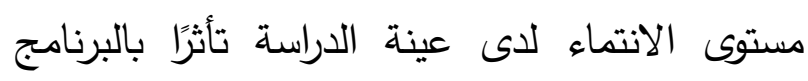

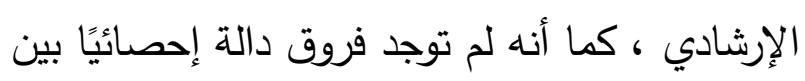
أفراد العينة تبعا للجنس. - كما أشارت دراسة (Humphreys,2011 ) إلى أن تُعان للتعليم العالي دورًا هامًا في تتمية المواطنة الفعالة بين

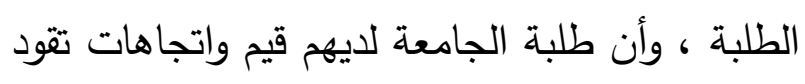

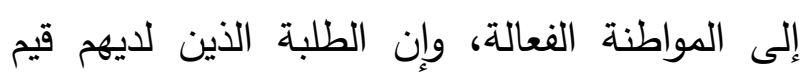

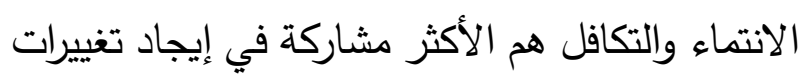
إيجابية تجاه الاخرين. 
r- توجد علاقة ذات دلالة إحصائية بين المناخ

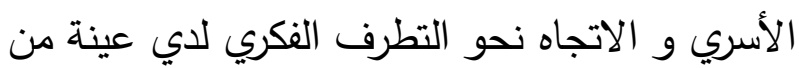

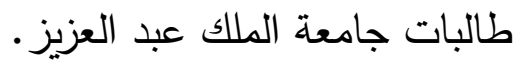
r- توجد علاقة ذات دلالة إحصائية بين الاتجاه نحو لعرئ

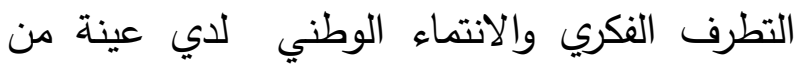
طالبات جامعة الملك عبد العزيز • ع- من المتوقع أن يتغير حجم الارتباط لدى أفراد عينة الدراسة بين الانتماء الوطني والاتجاه نحو التطرف الفكري بعد العزل الإحصائي للمناخ الأسري. ه-توجد فروق ذات دلالة احصائية بين عينة الدراسة في المناخ الأسري تعزي للتخصص. 1-توجد فروق ذات دلالة إحصائية بين عينة الدراسة في الاتجاه نحو التطرف الفكري تعزي للتخصص. V- توجد فروق ذات دلالة إحصائية بين عينة الدراسة في الانتماء الوطني تعزي للتخصص. - إجراءات الدراسة : أ- منهج الدراسة : نظرا لأن الهدف من الدراسة هو التعرف على المناخ الأسري وعلاقته بكل من الانتماء الوطني والاتجاه نحو التطرف الفكري فإن المنهج المناسب هو المنهج الوصفي الطريقة الارتباطية والمقارنة. ب- مجتمع الدراسة : طالبات جامعة الملك عبد العزيز بجدة وبكلياتها

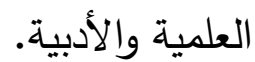

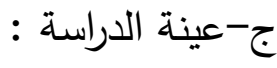

اجتماعية - القدرة على تحمل المسؤولية - القدرة على تقبل نقد الآخرين - القدرة على اتخاذ القرار - القدرة على مساعدة الآخرين ، ودراسة -أكدت أغلب الدراسات الخاصة بمتغير التطرف ودرسه الفكري على آثاره السلبية على الثباب فقد أوضحت

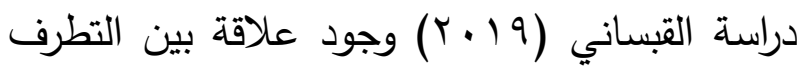
الفكري والاتجاه نحو الجريمة، ودراسة خليفة وأخرين (T) فقد أظهرت النتائج وجود علاقة ارتباطية بين التطرف الفكري والأفكار السلبية وأحادية الرؤية

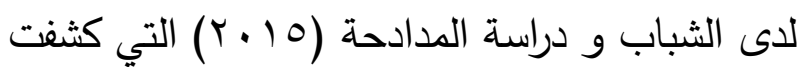
عن وجود علاقة إيجابية بين الضغوط النفسية والتطرف الفكري و دراسة الفريجات (10 • ب) التي وجود علاقة ارتباطية دالة بين المناخ الأسري والصحة درله النفسية، ودراسة (Muddry, et al, 2007) التي أكدت على أن العلاقة الدافئة بين الطالب وإخوته والتعبير العاطفي واتفاق الوالدين في التربية أسهمت التهات بشكل كبير في تحقيق مناخ أسري جيد وخفقت من

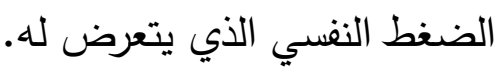

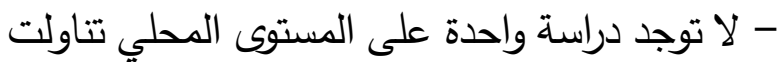

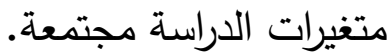
- فروض الاراسة : 1- توجد علاقة ذات دلالة إحصائية بين المناخ الأسري والانتماء الوطني لأي عينة من طالبات جامعة الملك عبد العزيز • 
• طريق التجزئة النصفية : بلغ معامل الارتباط بين

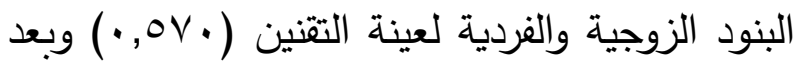

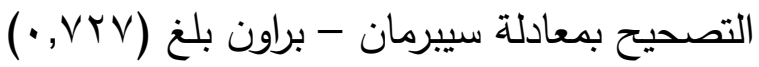

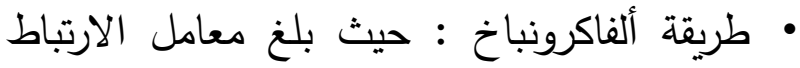
(الم)

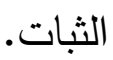
r- مقياس الاتجاه نحو التطرف الفكري : من إعداد

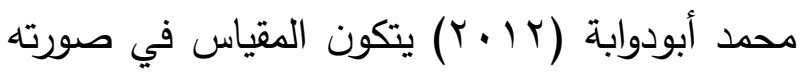
النهائية من ·0 عبارة موزعة على ثلاثة أبعاد وهي الاتجاه نحو التطرف (السياسي، الديني، الاجتماعي) ويوجد لكل عبارة خمسة اختيارات يقوم الطالب بإختيار أحدها وهي (موافق بشدة ، موافق، محايد، معارض،

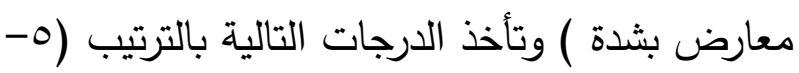

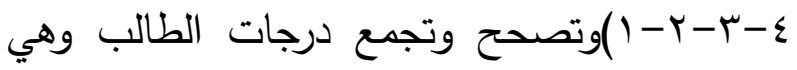
تمثل الدرجة الكلية على المقياس ويشير ارتفاع درجات الطالب بأنه يتسم باتجاهات متطرفة في استجاباته والدرجة المنخفضة تثير إلى اعتدال الفرد في مواقفه وآرائه وابتعاده عن التطرف. الخصائص السيكومترية للمقياس في الداستة الحالية :

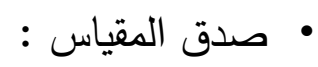
استخدمت الباحثتان طريقة صدق الاتساق الداخلي للتحقق من صدق المقياس وذلك بإيجاد معامل الارتباط بين درجة كل فقرة مع الدرجة الكلية للبعد ملدي الذي تتنمي إليه ، و درجة كل بعد من أبعاد الاتجاه نحو التطرف والدرجة الكلية للمقياس وذلك بعد تطبيقه لئه
اختيرت عينة عشوائية من الطالبات قوامها (ع ( ) طالبة ، من الكليات العلمية و الكليات الأدبية.

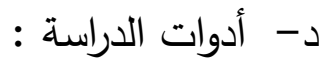
استخدمت الباحثتان الأدوات التالية : 1- مقياس المناخ الأسري : إعداد عفراء ابراهيم خليل

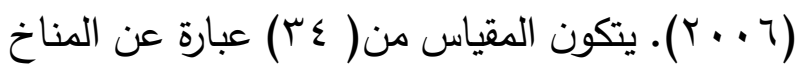

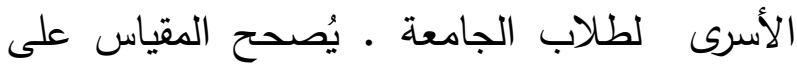
تقدير ثلاثي ووضع درجة لكل استجابة (Y، T ، ( )

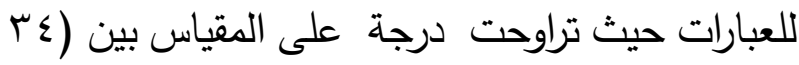

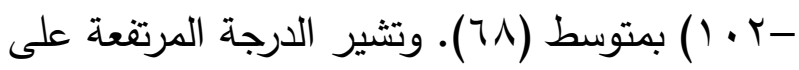

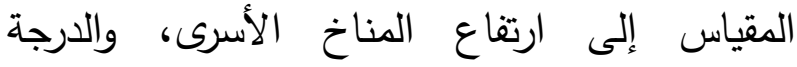
المنخفضة إلى انخفاض المناخ الأسرى لدى الطالبة.

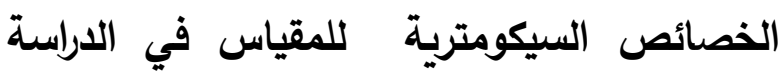

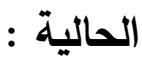
صدق المقياس : استخدمت الباحثتان طريقة صدق الاتساق الداخلي للتحقق من صدق المقياس وذلك بإيجاد معامل الارتباط بين درجة كل فقرة مع الارجة الكلية للمقياس

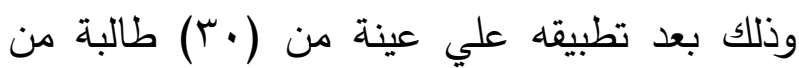

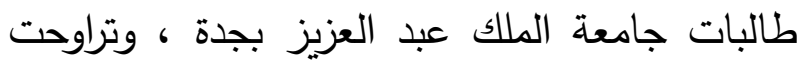

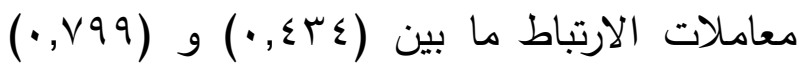
وجميعها دالة عند مستوي ( +., +، وبذلك يتضح أن المقياس يتسم بقدر من الصدق يسمح بتطبيقه في

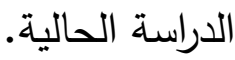

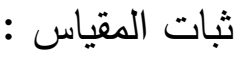
حُسِب ثبات المقياس بطريقتين : 
استخدمت الباحثتان طريقة صدق الاتساق الداخلي للتحقق من صدق المقياس وذلك بإيجاد معامل الارتباط بين درجة كل فقرة مع الدرجة الكلية للبعد الذي تتنمي إليه ، و درجة كل بعد من أبعاد الانتماء الوطني والدرجة الكلية للمقياس وذلك بعد تطبيقه علي العينة السابق الإشارة إليها، وتراوحت معاملات الارتباط بين درجة كل فقرة مع الدرجة الكلية للبعد

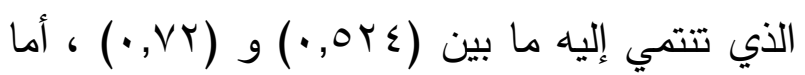

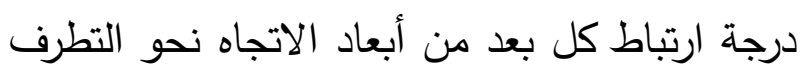

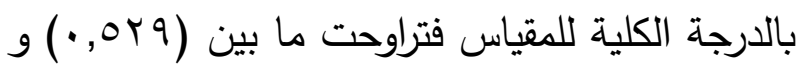

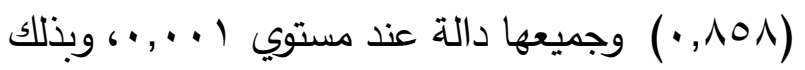

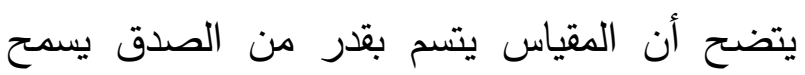
بتطبيقه في الدراسة الحالية

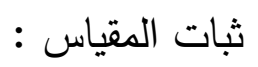
تم حساب ثبات المقياس: • طريق التجزئة النصفية : بلغ معامل الارتباط بين

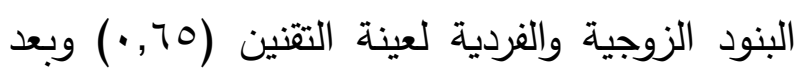

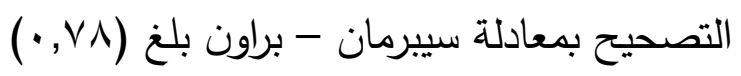

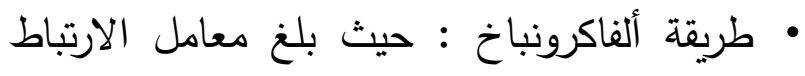

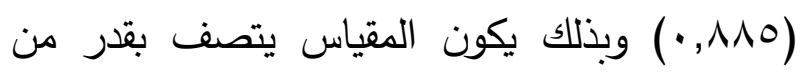
الثبات.

نتائج الاراسة : نتائج الفرض الأول : الذي ينص على :

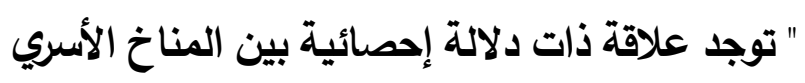

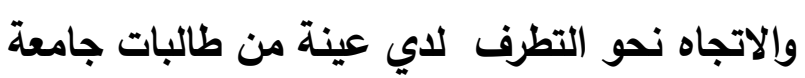

علي العينة السابق الإشارة إليها، وتراوحت معاملات

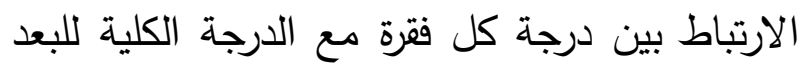

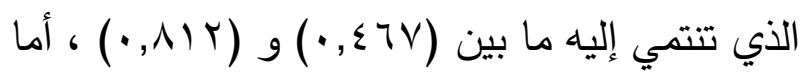

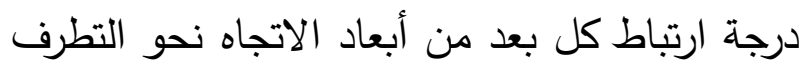

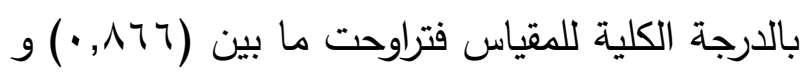

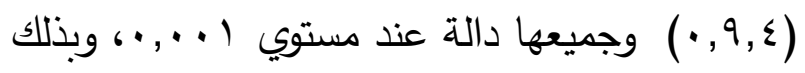
يتضح أن المقياس يتسم بقدر من الصدق يسمح دأس بتطبيقه في الدراسة الحالية

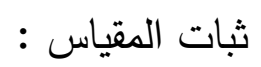
حسب ثبات الدقياس: • طريق التجزئة النصفية : بلغ معامل الارتباط بين

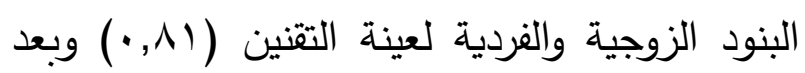
التصحيح بمعادلة سيبرمان - براون بلغ (9 ^, • )

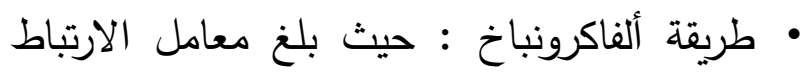

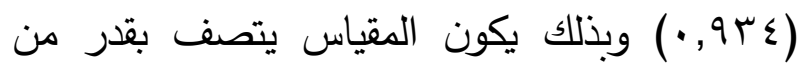
r-مقياس الانتماء الوطني: من إعداد أحمد فاروق

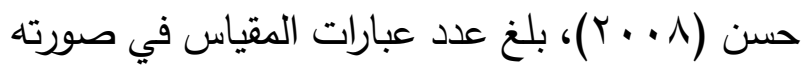

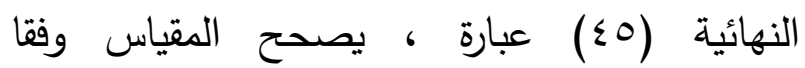
للاستجابات التالية (موافق -غبر متأكد -غير موافق) وتكون الدرجة على هذا الاختبار إذا كانت العبارات

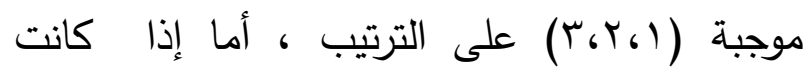
العبارات سالبة تكون الدرجات على التوالي (T، Y، ، ( ). الخصائص السيكومترية للمقياس في الداسلة الحالية :

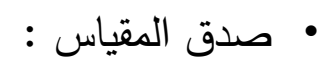


للتحقق من صحة هذا الفرض استخدم معامل ارتباط

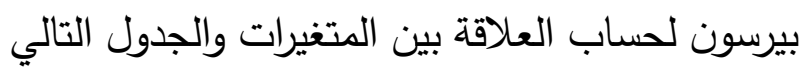
يوضح هذه النتائج : جدول (1) معاملات ارتباط بيرسون بين المناخ الأسري والاتجاه نحو التطرف الفكري والانتماء الوطني لاي عينة من طالبات

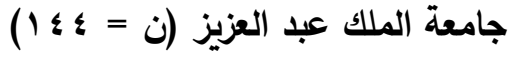

\begin{tabular}{|c|c|c|c|}
\hline مستوي الدلالة & المناخ الأسري & & المقياس \\
\hline 0.05 & $.197^{*}$ & الاتجاه نحو التطرف السياسي & \multirow{4}{*}{ التطرف الفكري } \\
\hline 0.01 & $.262 * *$ & الاتجاه نحو التطرف الديني & \\
\hline غير دالة & -.025 & الاتجاه نحو التطرف الاجتماعي & \\
\hline 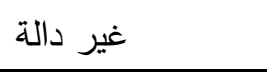 & .140 & الدرجة الكلية علي مقياس التطرف & \\
\hline
\end{tabular}

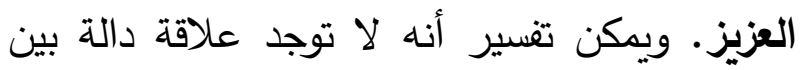
الدرجة الكلية للمناخ الاسري والدرجة الكلية للاتجاه نحو التطرف الفكري أن الاتجاه نحو التطرف الفكري

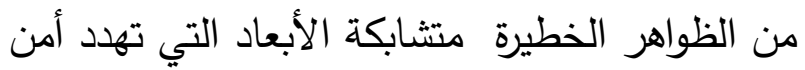

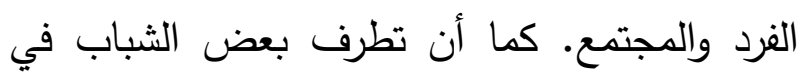
آرائهم وأفكارهم واتجاهاتهم نحو بعض القضايا الاجتماعية والسياسية والدينية يتشكل من خلال عملية التتشئة الاجتماعية ولكن من المهم أن نؤكد أن الأسرة ليست هي المؤسسة الوحيدة المسئولة عن تشكيل

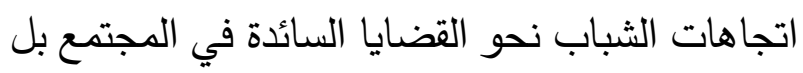
تتداخل الكثير من المؤسسات والهيئات في هذا مثل الإعلام، والمدرسة ، والجامعة والأصدقاء وهذا يتقق

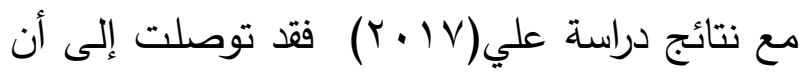
الجامعة تسهم بدرجة كبيرة في تتمية اتجاهات الفرد

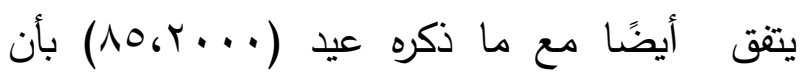
الاتجاهات تتكون من خلال الموضوعات التي تحيط

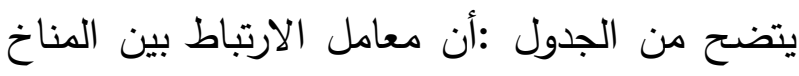

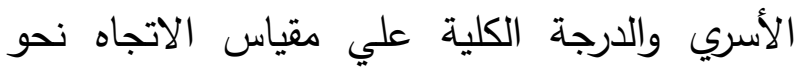

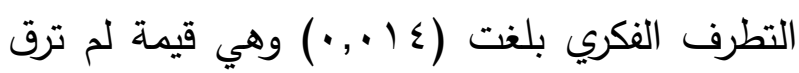
لمستوي الدلالة ولم يرق لمستوي الدلالة الاحصائية

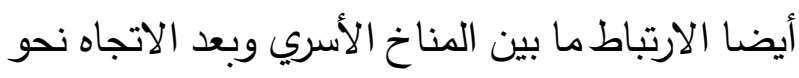

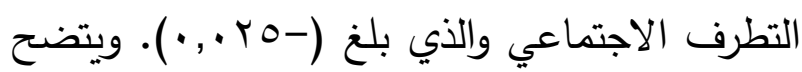
أيضًا وجود علاقة ارتباطية موجبة وذات دلالة إحصائية بين المناخ الأسري وبُعدي الاتجاه نحوديه

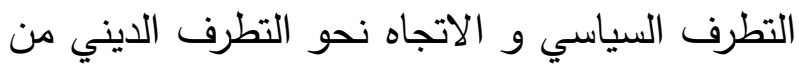
مقياس الاتجاه نحو التطرف الفكري حيث بلغا معاملي

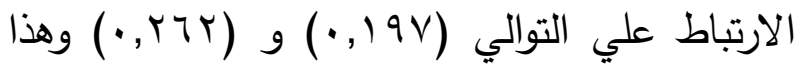
يعني أن الزيادة في أحد المتغيرين يقابلها زيادة في المتغير الآخر والعكس صحيح · وبهذا نقبل جزئيًا فرض الدراسة الأول القائل بوجود علاقة ذات دلالة

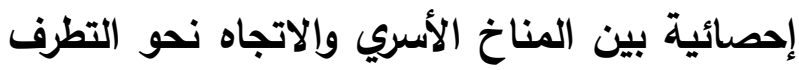

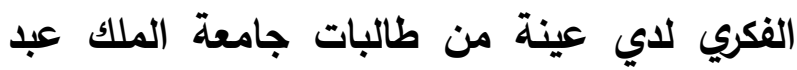

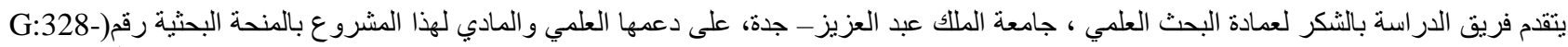
IV الصفحة 
بالفرد من أشخاص وطبقات أو عقائد اجتماعية ، أو " توجد علاقة ذات دلالة إحصائية بين المناخ الأسري

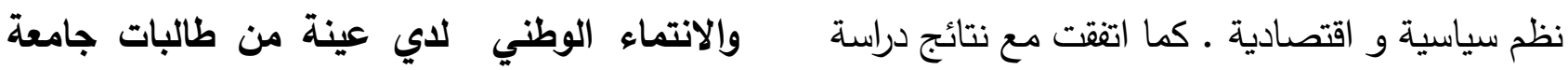

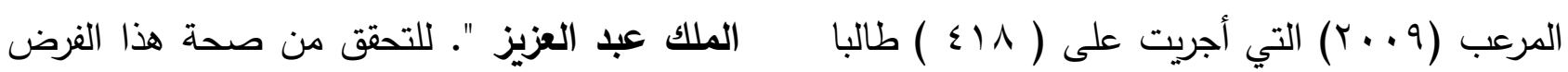
من طلبة كلية التربية في مدينة حائل أن أقل درجات استخدم معامل ارتباط بيرسون لحساب العلاقة بين

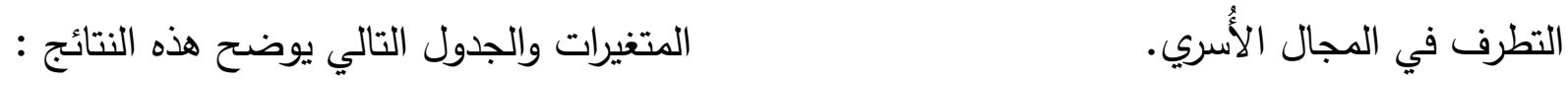

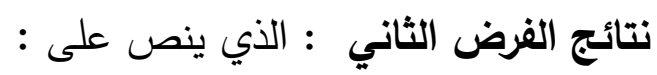
جدول (Y) معاملات ارتباط بيرسون بين المناخ الأسري والانتماء الوطني لاي عينة من طالبات جامعة الملك عبد العزيز (ن = ؛ ؛ 1)

\begin{tabular}{|c|c|c|c|}
\hline مستوي الدلالة & المناخ الأسري & & 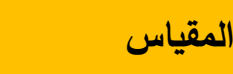 \\
\hline 0.05 & $.188^{*}$ & مكانة الفرد وقيمته داخل الوطن & \multirow[t]{7}{*}{ | الانتماء الوطني | } \\
\hline غير دالة & .050 & العلاقات داخل الوطن & \\
\hline غير دالة & .042 & الرضا عن الوطن & \\
\hline 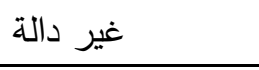 & .012 & المشاركة والتعاون وتحمل المسؤولية & \\
\hline غير دالة & -.056 & تقبل قيم ومعايير الوطن & \\
\hline 0.01 & $-.230 * *$ & التضحية والحفاظ علي الوطن & \\
\hline غير دالة & .024 & الدرجة الكلية علي مقياس الانتماء & \\
\hline
\end{tabular}

"** معاملات دالة عند مستوي معنوية ا +, .

" معاملات دالة عند مستوي معنوية 0 .,

الوطن ) وجدت علاقة بينه وبين المناخ الأسري بلغت

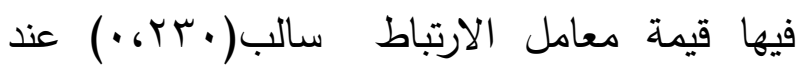
مستوى ا •.، •لذا اتخذت العلاقة اتجاها عكسيا مما يدل على انه كلما ارتفعت درجة المناخ الاسري تقل

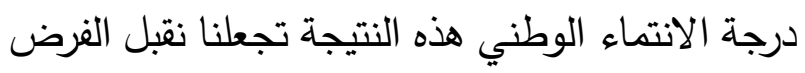

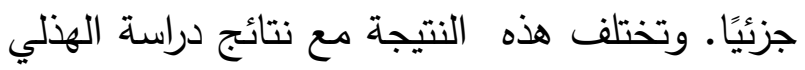

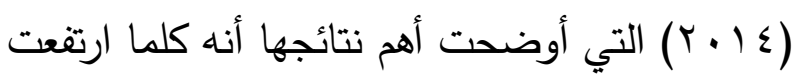
درجة الأمان الاسري والتضحية والتعاون الأسري
يتضح من الجدول : أن غالبية معاملات الارتباط بين

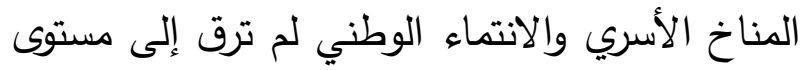
الدلالة الإحصائية. كما اتضح وجود علاقة دالة بين المناخ الاسري وبعد (مكانة الفرد وقيمته داخل الوطن

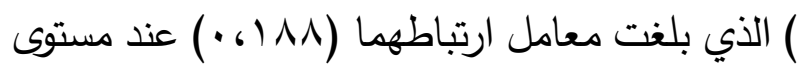
(0، •) فنجد العلاقة اتخذت اتجاهًا إيجابيًا مما يدل

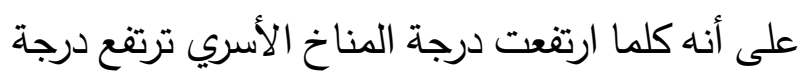

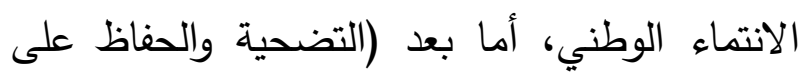


كانت هناك قدرة على تكوين علاقات اجتماعية، تحمي أبناءها من الأفكار اللاعقلانية المتطرفة

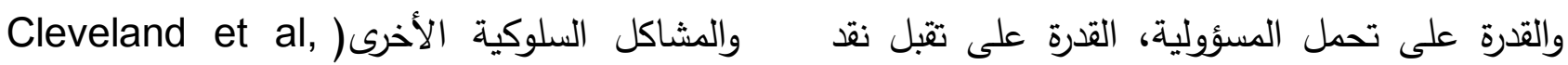

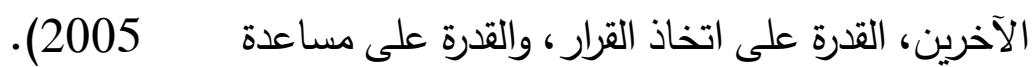

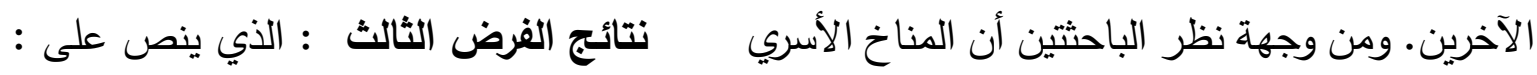

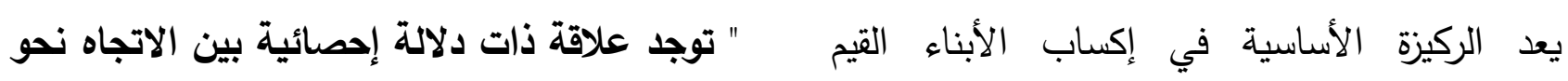

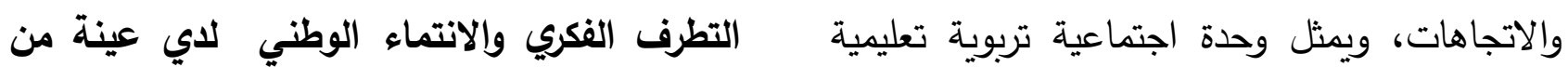

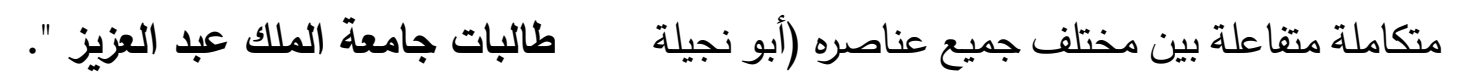

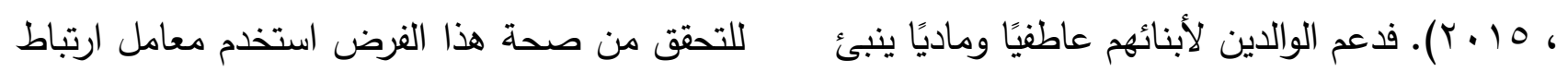
بالعديد من النتائج الإيجابية: مثل ارتفاع مستوى بيرسون لحساب العلاقة بين المتغيرين والجدول التالي

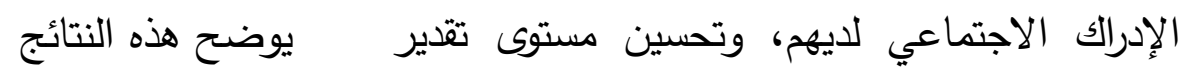
الذات، ورفع مستوى الكفاءة العقلية ، وزيادة انتمائهم الوطني . كما أن أساليب المعاملة الوالدية الإيجابية

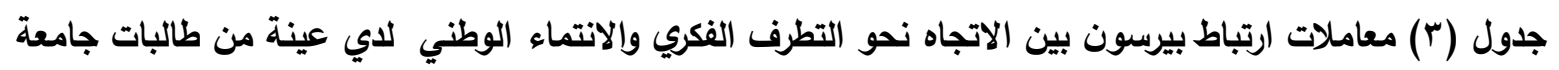

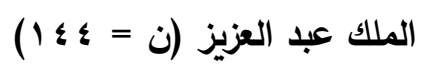

\begin{tabular}{|c|c|c|c|c|}
\hline \multicolumn{4}{|c|}{ الاتجاه نحو التطرف الفكري } & \multirow[t]{2}{*}{ الانتماء الوطني } \\
\hline التطرف درجة كلية & التطرف الاجتماعي & التطرف الديني & التطرف السياسي & \\
\hline$-.410^{* *}$ & $-.515^{\circ *}$ & -.156 & $-.346^{* *}$ & مكانة الفرد وقيمته داخل الوطن \\
\hline$-.412^{* *}$ & $-.519^{* *}$ & -.154 & $-.350^{* *}$ & العلاقات داخل الوطن \\
\hline$-.312^{* *}$ & $-.456^{* *}$ & -.036 & $-.252^{* *}$ & الرضا عن الوطن \\
\hline$-.271^{* *}$ & $-.309^{* *}$ & -.120 & $-.256^{* *}$ & المشاركة والتعاون وتحمل المسؤولية \\
\hline$-.535^{* *}$ & $-.559^{* *}$ & $-.319^{* *}$ & $-.500^{* *}$ & تقبل قيم ومعايير الوطن \\
\hline
\end{tabular}

G:328- يتقام فريق الدر اسة بالثكر لعمادة البحث العلمي ، جامعة الملك عبد العزيز - جدة، على دعمها العلمي والمادي لهذا المشروع بالمنحة البحثية رقمة 19 الصفحة 19 


\begin{tabular}{|c|c|c|c|c|}
\hline$-.562^{* *}$ & $-.439^{* *}$ & $-.522^{* *}$ & $-.556^{* *}$ & التضحية والحفاظ علي الوطن \\
\hline$-.529^{* *}$ & $-.608^{* *}$ & $-.258^{* *}$ & $-.473^{* *}$ & الانتماء درجة كلية \\
\hline
\end{tabular}

"* " معاملات دالة عند مستوي معنوية ا.,.

أثباه بالسلوك الإجرامي، وتؤكد كثير من الدراسات منها دراسة القبساني (9 (19 ب) ارتباط التطرف الفكري بالاتجاه نحو الجريمة، كما أكدت دراسة خليفة

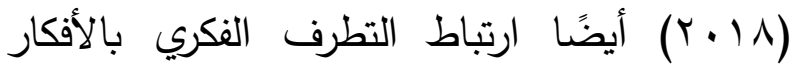

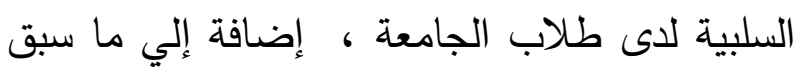

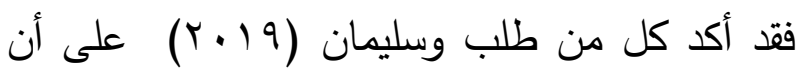
التطرف الفكري يعكس مدى تردي نوعية السلوك

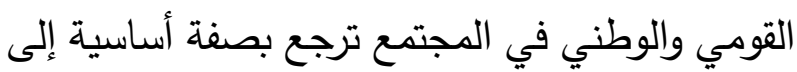
عدم الإحساس بالمسئولية الاجتماعية وضعف شعورهم بالانتماء الوطني وهذا ما أكدت عليه نتائج دراستهم لوجود علاقة دالة بين المسئولية الاجتماعية وقيم المواطنة عند طلاب الجامعة . نتائج الفرض الرابع: الذي ينص على : " من المتوقع أن يتغير حجم الارتباط لاى أفراد عينة

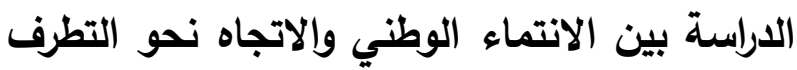
الفكري بعد العزل الأحصائي للمناخ الأسري". للتحقق من صحة هذا الفرض تم استخدام معامل الارتباط الجزئي لحساب العلاقة بين الانتماء الوطني والاتجاه نحو التطرف الفكري بعد العزل الإحصائي

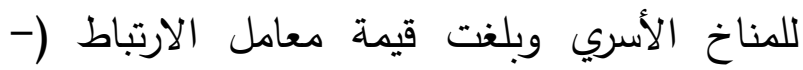

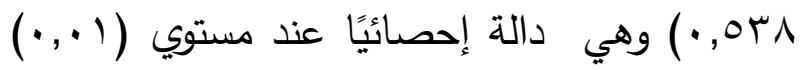
وبالرجوع لقيمة معامل ارتباط بيرسون للعلاقة بين الانتماء الوطني والاتجاه نحو التطرف الفكري في لئه
يتضح من الجدول: أن معظم معاملات الارتباط بين الاتجاه نحو التطرف الفكري والانتماء الوطني كانت

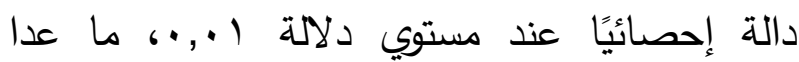
العلاقات ما بين بعد التطرف الديني من مقياس

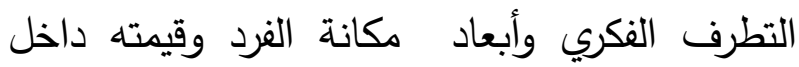
الوطن، العلاقات داخل الوطن ، الرضا عن الوطن، و المشاركة والتعاون وتحمل المسؤولية من مقياس الانتماء الوطني، حيث لم ترق معاملات الارتباط بينهح إلي مستوي الدلالة الإحصائية ـ نلاحظ من الجدول

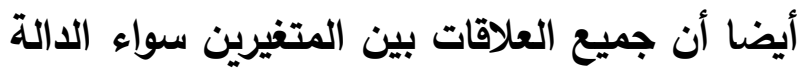

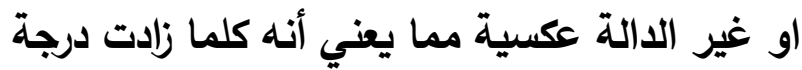
الانتماء الوطني قلت درجة التطرف الفكري. ويمكن تفسير هذه النتيجة في ضوء مفهوم التطرف الفكري الذي يعني التشدد وتجاوز الحد، والميل للعدوان والعنف ، والتطرف هو كل سلوك يخالف المعايير الاجتماعية ، وهو مخالفة ما تجمع عليه الامة سواء دينيًا أو اجتماعيًا أو سياسيًا وهو بذلك يكون سلوك

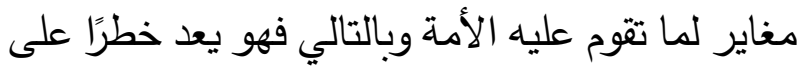

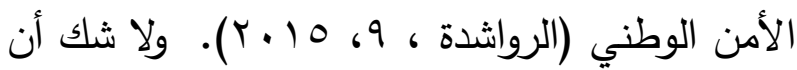
الفرد الذي يمتلك هذه الاتجاهات المتطرفة لا يشعر الترون

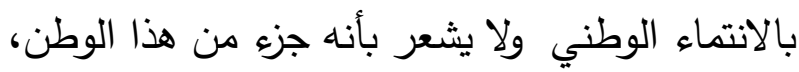

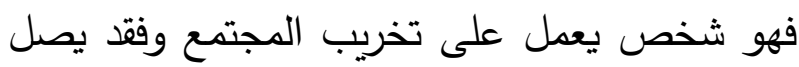
به الأمر لقتل الأبرياء ونهب ممتلكات الغير ، فسلوكه 
والاجتماعية والعلمية والروحية والأخلاقية والترويحية وغيرها، والعمل على تتمية قدرات ومهارات مفاتيح النجاح في الحياة والتغلب على مشكلاتها وشدائدها، وغرس القيم و الأفكار والمشاعر الإيجابية، حتى يستطيع الفرد أن يفيد نفسه ومجتمعه، فيشعر بأهميته وقيمته ونجاحه في الحياة ويحقق هويته في المجتمع. ولا شك أنه إذا زاد الانتماء الوطني قلت الاتجاهات الفكرية المتطرفة. فالمناخ الاسري ينبئ بالصحة النفسية وهذا ما أكدته نتائج دراسة قمر (V V • (Y)م) نتائج الفرض الرابع : الذي ينص على : "توجد فروق ذات دلالة إحصائية بين عينة الدراسة في المناخ الأسري تعزي للتخصص" . للتحقق من صحة هذا الفرض استخدام اختبار ت لعينتين مستقلتين والجدول التالي يوضح هذه النتائج:
جدول (Y) نجد أنه بلغ (-9Y,o, •) وهي دالة احصائيًا عند مستوي (1 (., ) ) ، بمقارنة قيمة معامل ارتباط بيرسون بقيمة معامل الارتباط الجزئي نلاحظ ارتفاع قيمة معامل الارتباط الجزئي ، وبناء علي هذه النتيجة ، فإنه يمكن النظر إلي المناخ الأسري بوصفه متغيرًا وسيطًا في العلاقة بين الانتماء الوطني والاتجاه نحو التطرف الفكري ، ومن ثم يمكن التتبؤ بأنه في ظل غياب المناخ الأسري يمكن أن تتشط الآثار السلبية للتطرف الفكري التي منها انخفاض الانتماء الوطني كما يمكن تفسير هذه النتيجة أيضًا بأن المناخ الأسري السوى ينمي للى الأفراد القدرة على التمسك بالقيم الخاصة وخلق حالة من الحفاظ على انتمائهم الوطني وعدم السماح للمتغيرات الناجمة عن الانحرافات الأخلاقية أن تؤثر عليهم .من خلال الاهتمام بتحقيق التوازن بين الجوانب الجسمية والعقلية

جدول (ء) نتائج اختبار(ت) لدلالة الفروق بين عينة الدراسة في المناخ الأسري وفقا للتخصص (نظري - عملي)

\begin{tabular}{|c|c|c|c|c|c|c|c|}
\hline مستوي الدلالة & درجات الحرية & قيمة ت & $\varepsilon$ & م & العدد & المجموعة & المتغير \\
\hline \multirow[t]{2}{*}{ غير دالة | } & \multirow[t]{2}{*}{142} & \multirow[t]{2}{*}{-1.895} & 5.41 & 73.47 & 118 & كليات نظرية & \multirow[t]{2}{*}{ المناخ الأسري } \\
\hline & & & 9.27 & 76.04 & 26 & كليات عملية & \\
\hline
\end{tabular}

يتضح من الجدول السابق عدم وجود فروق دالة 1,190) وهي غير دالة إحصائيا • وبذلك نرفض إحصائيًا بين متوسطي درجات طالبات الكليات الفرض الرابع القائل بأن هنالك فروقًا ذات دلالة النظرية وطالبات الكليات العلمية علي الدرجة الكلية إحصائية بين عينة الدراسة في المناخ الأسري تعزي لمقياس المناخ الأسري حيث بلغت قيمة ت (- للتخصص. وقد اختلفت نتيجة الدراسة مع نتائج دراسة 
ميرة (r (r) التي أظهرت وجود فروق في المناخ الإنسانية، وطبيعة العلاقات الأسرية داخل المناخ

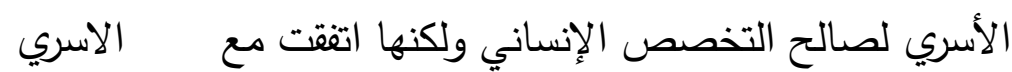

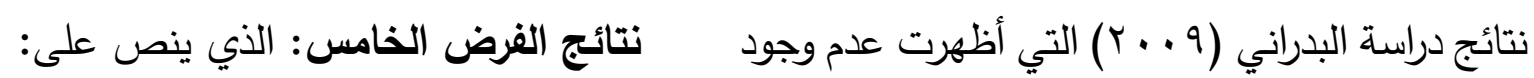

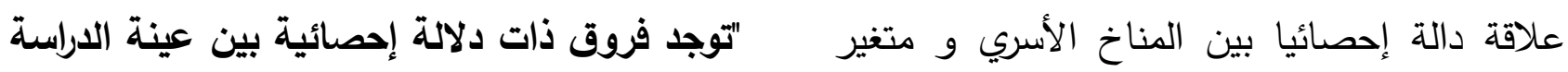
التخصص (علمي - أدبي). كما يمكن تفسير النتيجة في الاتجاه نحو التطرف الفكري تعزي للتخصص

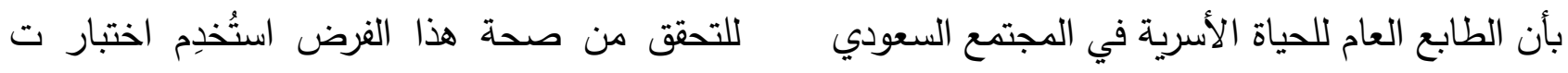

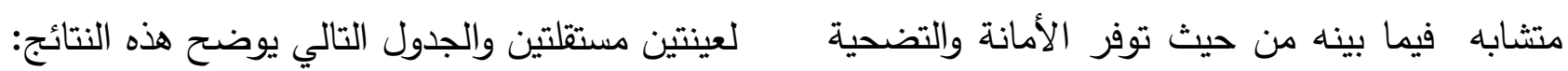

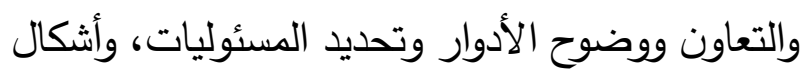
الضبط، ونظام الحياة، وكذلك أسلوب إثباع الحاجات جدول (ه) نتائج اختبار(ت) لدلالة الفروق بين عينة الدراسة في الاتجاه نحو التطرف الفكري وفقا للتخصص (نظري - عملي)

\begin{tabular}{|c|c|c|c|c|c|c|c|}
\hline |مستوي الدلالة & درجات الحرية & قيمة ت & $\varepsilon$ & م & 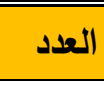 & المجموعة & المتغير \\
\hline \multirow{2}{*}{ غير دالة } & \multirow[t]{2}{*}{142} & \multirow[t]{2}{*}{-1.51} & 8.82 & 38.60 & 118 & كليات نظرية & \multirow{2}{*}{ التطرف السياسي } \\
\hline & & & 11.89 & 41.69 & 26 & كليات عملية & \\
\hline \multirow[t]{2}{*}{0.05} & \multirow[t]{2}{*}{142} & \multirow[t]{2}{*}{-2.18} & 7.04 & 36.31 & 118 & كليات نظريـة & \multirow[t]{2}{*}{ التطرف الديني } \\
\hline & & & 10.73 & 40.00 & 26 & كليات عملية & \\
\hline \multirow[t]{2}{*}{ غير دالة } & \multirow[t]{2}{*}{142} & \multirow[t]{2}{*}{-1.21} & 11.72 & 45.88 & 118 & كليات نظرية & \multirow[t]{2}{*}{ التطرف الاجتماعي } \\
\hline & & & 12.56 & 49.00 & 26 & كليات عملية & \\
\hline \multirow[t]{2}{*}{ غير دالة } & \multirow[t]{2}{*}{142} & \multirow[t]{2}{*}{-1.77} & 24.28 & 120.79 & 118 & كليات نظرية & \multirow[b]{2}{*}{ تنطرف درجة كلية } \\
\hline & & & 31.99 & 130.69 & 26 & كليات عملية & \\
\hline
\end{tabular}

الديني لصالح طالبات الكليات العملية حيث بلغت

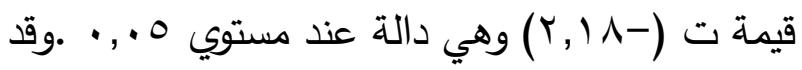
اتقتت هذه النتيجة مع نتائج دراسة كل خليفة وآخرين

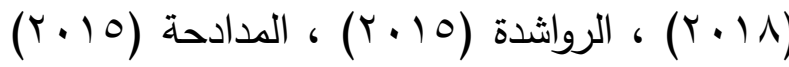

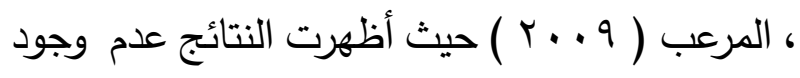

يتضح من الجدول السابق عدم وجود فروق دالة إحصائيا بين متوسطي درجات طالبات الكليات العملية وطالبات الكليات النظرية علي الدرجة الكلية لمقياس الاتجاه نحو التطرف وبعدي التطرف الاجتماعي والتطرف السياسي، ويتضح من الجدول

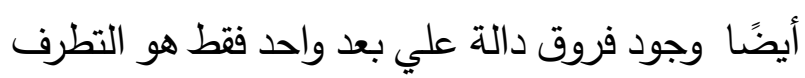


"توجد فروق ذات دلالة إحصائية بين عينة الدراسة"

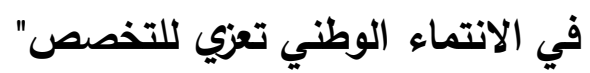
للتحقق من صحة هذا الفرض استُخدم اختبار ت لعينتين مستقلتين والجدول التالي يوضح هذه النتائج:

جدول (ا) نتائج اختبار(ت) لدلالة الفروق بين عينة الدراسة في الانتماء الوطني وفقا للتخصص (نظري - عملي)

\begin{tabular}{|c|c|c|c|c|c|c|c|}
\hline مستوي & درجات & قيمة ت & $\varepsilon$ & b & العدد الع & 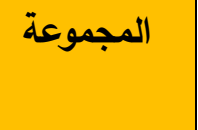 & 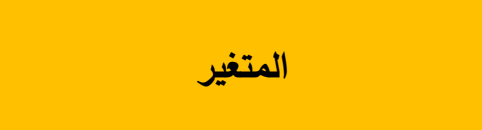 \\
\hline \multirow[t]{2}{*}{ غير دالة } & \multirow[t]{2}{*}{142} & \multirow[t]{2}{*}{-.258} & 2.64 & 18.54 & 118 & كليات نظرية & \multirow{2}{*}{ مكانة الفرد وقيمته داخل الوطن } \\
\hline & & & 2.88 & 18.69 & 26 & كليات عملية & \\
\hline \multirow[t]{2}{*}{ 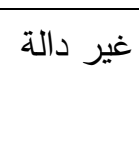 } & \multirow[t]{2}{*}{142} & \multirow[t]{2}{*}{.506} & 2.82 & 17.00 & 118 & كليات نظرية & \multirow[b]{2}{*}{ العلاقات داخل الوطن } \\
\hline & & & 2.75 & 16.69 & 26 & كليات عملية & \\
\hline \multirow[t]{2}{*}{ 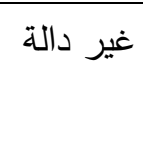 } & \multirow[t]{2}{*}{142} & \multirow[t]{2}{*}{-1.177} & 2.22 & 17.00 & 118 & كليات نظرية & \multirow[b]{2}{*}{ الرضا عن الوطن } \\
\hline & & & 2.45 & 17.58 & 26 & كليات عملية & \\
\hline \multirow[t]{2}{*}{ 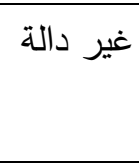 } & \multirow[t]{2}{*}{142} & \multirow[t]{2}{*}{-.417} & 2.02 & 16.43 & 118 & كليات نظرية & \multirow[b]{2}{*}{ المشاركة والتعاون وتحمل المسؤولية } \\
\hline & & & 2.04 & 16.62 & 26 & كليات عملية & \\
\hline \multirow[t]{2}{*}{ 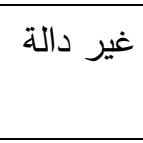 } & \multirow[t]{2}{*}{142} & \multirow[t]{2}{*}{1.431} & 2.15 & 18.83 & 118 & كليات نظرية & \multirow[b]{2}{*}{ تقبل قيم ومعايير الوطن } \\
\hline & & & 2.94 & 18.12 & 26 & كليات عملية & \\
\hline \multirow[t]{2}{*}{ غير دالة } & \multirow[t]{2}{*}{142} & \multirow[t]{2}{*}{1.423} & 1.49 & 16.38 & 118 & كليات نظرية & \multirow[b]{2}{*}{ التضحية والحفاظ علي الوطن } \\
\hline & & & 2.08 & 15.88 & 26 & كليات عملية & \\
\hline \multirow[t]{2}{*}{ 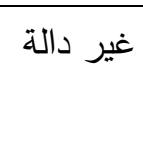 } & \multirow[t]{2}{*}{142} & \multirow[t]{2}{*}{.263} & 10.35 & 104.19 & 118 & كليات نظرية & \multirow[b]{2}{*}{ الانتماء درجة كلية } \\
\hline & & & 12.25 & 103.58 & 26 & كليات عملية & \\
\hline
\end{tabular}

في الانتماء الوطني تعزي للتخصص. وقد اتفقت

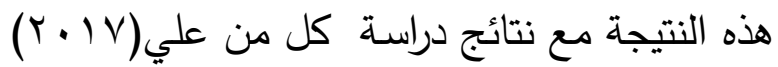
التي أظهرت عدم وجود فروق في درجة تمثل الطلبة

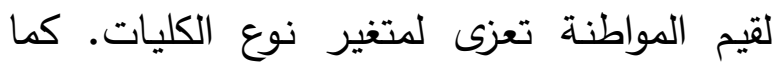
اختلفت مع دراسة الحارثي وعطية (9 ( ب م) حيث وجدت فروق ذات دلالة احصائية بين متوسطات
فروق دالة في الاتجاه نحو التطرف الفكري تعزى لمتغير التخصص الدراسي • لنائ نتائج الفرض السادس: الذي ينص على: 


\section{المقترحات البحثية:}

- دراسة بعنوان المناخ الأسري وعلاقته بالاتجاه نحو

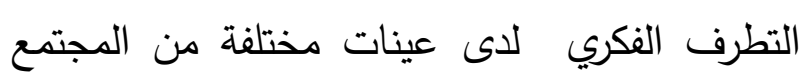

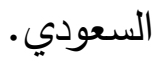
- فاعلية برنامج إرشادي جمعي لخفض الاتجاهات نحو التطرف الفكري لاى طالبات الجامعة. -دراسة سيكولوجية المتطرف فكريا. -الإعلام الجديد والأمن الفكري لدى عينة من الثباب السعودي. شكر وتقدير يتقدم فريق الدراسة بالثكر لعمادة البحث العلمي ،

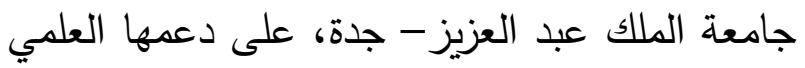

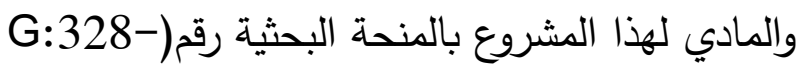

المراجع

-الأميري، أحمد علي أحمد(ب ا • Y). فاعلية برنامج إرشادي لتتمية الانتماء الوطني لدي طبة جامعه تعز ،

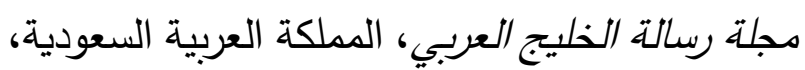
.1 $\leq \cdot-7 \cdot 64$

-بدرانة ، أحمد، فياض ، يحي، عيروط ، مصطفى

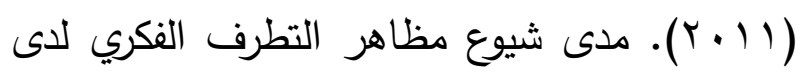
طلبة الجامعة الأردنية وعلاقتها بالعوامل الاقتصادية

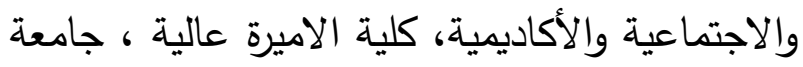
البلقاء التطبيقية ـ
درجات عينة الدراسة على مقياس الانتماء الوطني تبعا لنوع التعليم لصالح الطالبات بالكليات العملية،

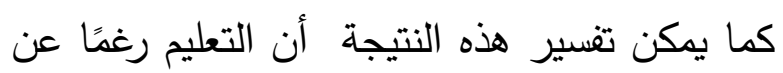
اختلاف التخصصات يخلق نوع من الوعي والمسئولية الاجتماعية تجاه المجتمع الذي يعيش فيه الفرد والوعي مرتبط بإدراك الأخطار الفكرية التي يمكن أن تهدد الأفراد وبالتالي تؤدي إلى فقدان التران الانتماء الوطني.

\section{التوصيات: - الت}

في ضوء النتائج التي توصلت إليها الدراسة فإنه يمكن تقديم التوصيات الآتية : -تفعيل الدور الذي تقوم به أجهزة الإعلام في توجيه

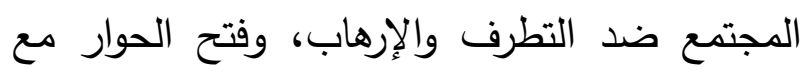
الشباب من قبل شخصيات مثقفة لهم تقديرهم عند

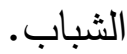
- إعداد ندوات ومحاضرات توعوية للآباء والأمهات تعزز مفهوم الأمن الفكري داخلهم.

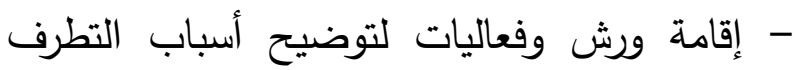
الفكري في المجتمع، والطرق التي يمكن بها مناهضة التطرف الفكري. -التنقيح الدائم للمقررات الدراسية والموضوعات التي قد تتعلق بالتطرف الفكري . -العمل على تقديم برامج إرشادية عن أهمية الأسرة ودورها في زيادة الانتماء الوطني لدى الأبناء .

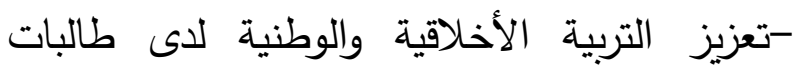

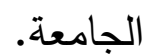


النفسية للى طلبة جامعة الأزهر بغزة، رسالة ماجستير، كلية التربية ، جامعة الأزهر ، غزيه

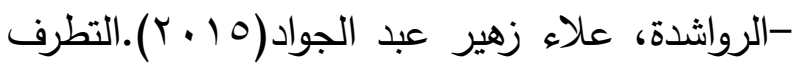
الأيديولوجي من وجهة نظر الثباب الأردني :دراسة

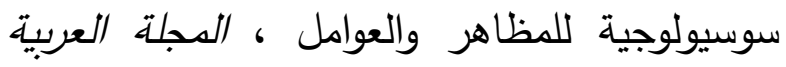

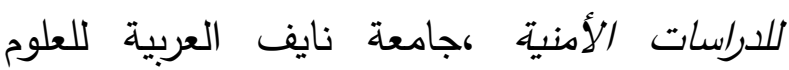

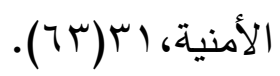

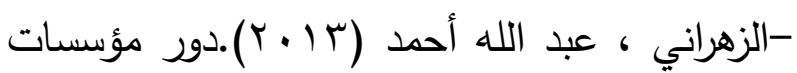
التعليم العالي بالمملكة العربية السعودية في مواجهة

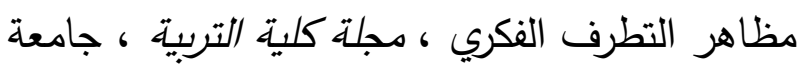

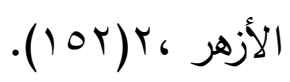

-السعود ، حنان عبيد(10 ـ ب). المتطلبات المهارية للاختصاصيين الاجتماعيين المتعاملين مع ضحايا الأفكار المتطرفة في ضوء منظور الممارسة المهنية العامة، المجلة العربية للدراسات الأمنية، اسب (YT). - السلمى، فاطمة عايض (ع ا • Y).دور المدرسة الثانوية في مواجهة الإرهاب وتعزيز الانتماء الوطني

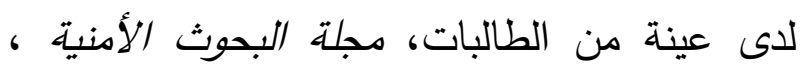

$$
\text { العدد(OV). }
$$

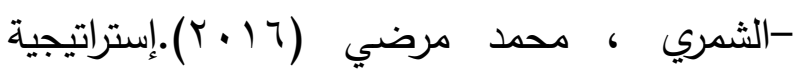
مقترحة لتوعية الشباب الكويتي من مخاطر الإرهاب

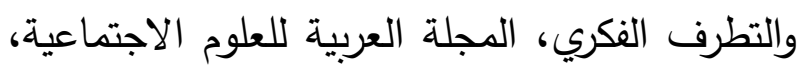

$$
\text { . }
$$

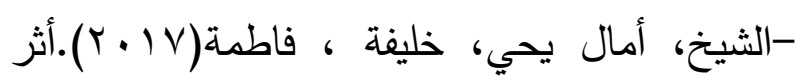

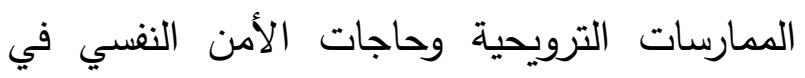
مواجهة الاتجاه نحو التطرف للى الثباب السعودي
-البدراني، فاطمة محمد صالح(9 . . ب).المناخ الاسري لدى طلبة جامعة الموصل، مجلة كلية التربية

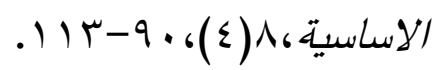

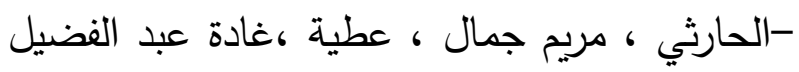

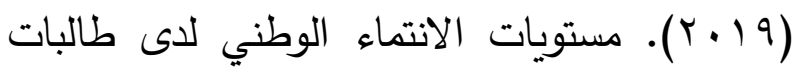
الجامعات السعودية : دراسة تطبيقية على طالبات

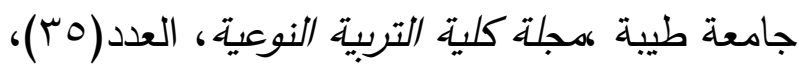
جامعة القاهرة.

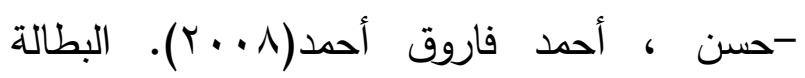
والانتماء الوطني لدى خريجي جامعة المنيا: دراسة

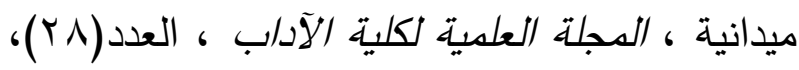
جامعة اسيوط . مئ.

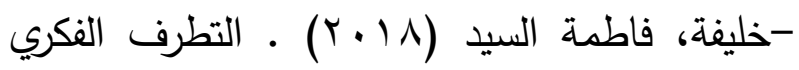
وعلاقته بالقابلية للأستهواء وإدمان شبكات التواصل الاجتماعي لدى عينة من طلاب الجامعة، مجلة

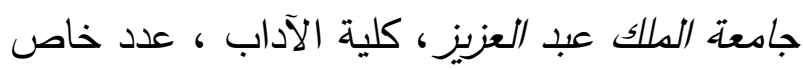
بأبحاث الملتقى العلمي الأول لكلية الآداب والعلوم

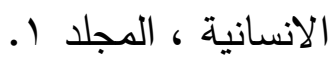

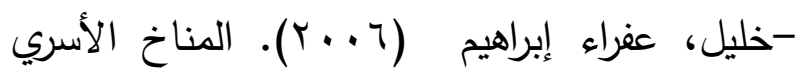

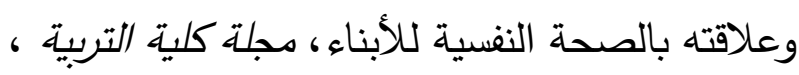

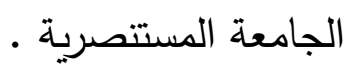

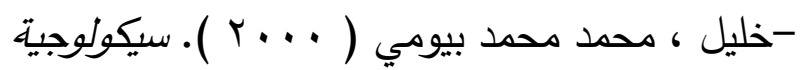

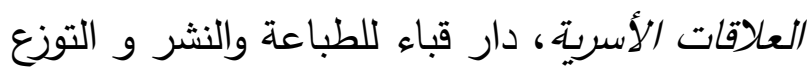
، القاهرة.

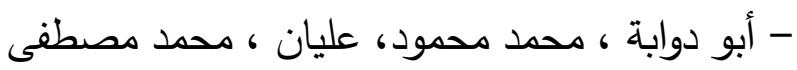

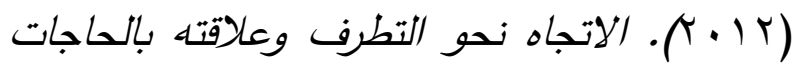


-القبساني، سمية سالم عبد الرحمن (9 (ب). التطرف الأيديولوجي كمنبئ للاتجاه نحو الجريدة للى لئي عينة من الشباب السعودي ، رسالة ماجستير ، كلية

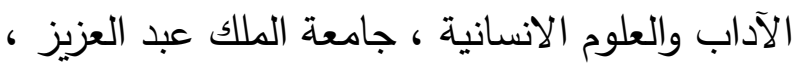

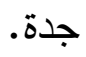

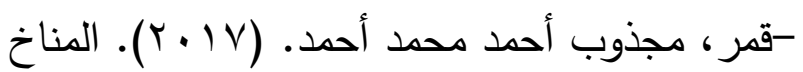
الأسري وعلاقته بالصحة النفسية والثعور بالذنب: دراسة ميدانية على عينة من طلبة كلية التربية جامعة دنقلا السودان. فلسطين: مجلة جامعة القدس الدفتوحة للأبحاث والدراسات التربوية والنفسية، العدد ( V V). -كفافي، علاء الدين ( 1999 ) الإششاد والعلاج النفسي الاسري، القاهرة :دار الفكر العربي.

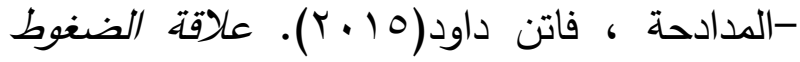

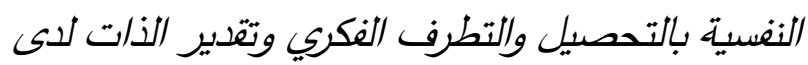
طلبة جامعة مؤته، رسالة ماجستير، كلية العلوم

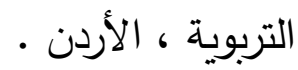

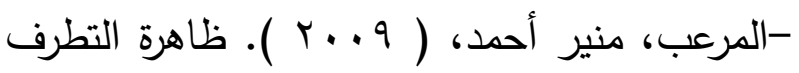
الفكري والتربوي عند طلاب كليات التربية للبنين في مدينة حائل. المظاهر والأسباب والحلول المقترحة 》دراسة ميدانية «ه مجلة القراءة والمعرفة. عدد 19 .

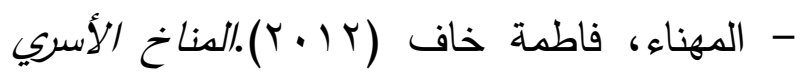
وعلاقته بالتنكير الإبداعي لدى طلبة جامعة الجوف،

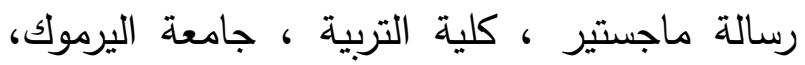

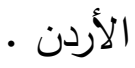

في ضوء بعض المتغيرات الديموغرافية ، مجلة مركز

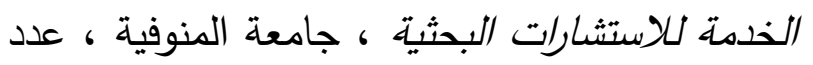

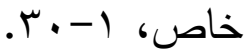
الصبوة ، محمد نجيب(r ا ـ ب).الإنحراف الفكري وأثره على الأمن الوطني العام في جمهورية مصر العربية

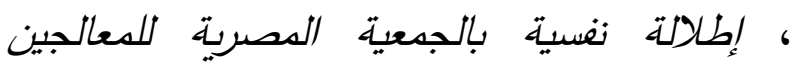
النفسيين. - طلب، أحمد على ، سليمان ،عمرو

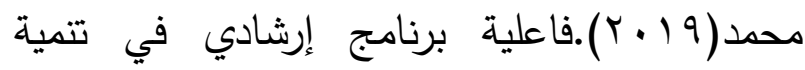
المسئولية الاجتماعية وتعزيز قيم المواطنة لدى طلاب الجامعة، المجلة التربوية ، العدد (9ه)، كلية التربية - علي، حمدي أحمد عمر(Y V • (Y). دور الجامعة في تتمية قيم المواطنة وتمثلها لدى الطلاب في ظل تحديات العولمة : دراسة ميدانية لعينة من طلبة

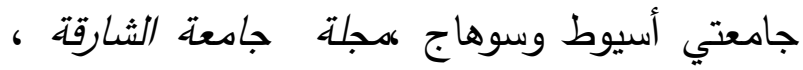

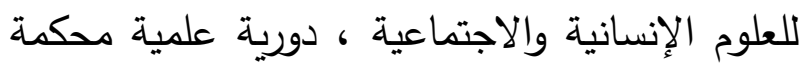
.(1) 1 纟 -عيد ، محمد إبراهيم ( (......). علم النفس الاجتماعي ، مكتبة زهراء الثرق ، القاهرة.

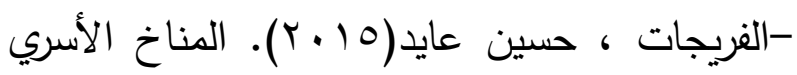
وعلاقته ببعض مظاهر الصحة النفسية لاى مجموعة من طلبة وطالبات كلية الدراسات الإسلامية والعربية في دبي، مجلة كلية التربية ، ب( ع ب (1)، جامعة الازهر 
كولبرج لاى طلبة جامعة الأزهر بغزة ، مجلة دراسات

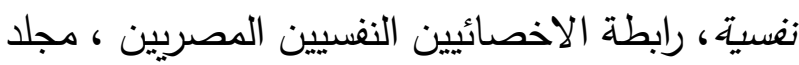
( T)

\section{المراجع الانجليزية}

-Coleman, J. (2014) . Working With Troubled Adolescents-

United States of America: International Psychotherapy Institute

-Cleveland MJ, Gibbons FX, Gerrard M, Pomery EA, Brody GH.

(2005). The Impact of Parenting on Risk Cognitions and Risk

Behaviour: A study of Mediation and Moderation in a Panel of African American Adolescents . Child Department. 76(4): 900916

-Dandagal, I S.N., \& Yarriswami, M.C. (2017).A Study of Family Climate in Relation to Academic Achievement of Secondary
-ميرة، أمل كاظم ().المناخ الأسري وعلاقته بالتكيف

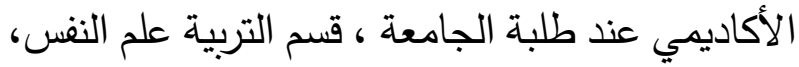
كلية التربية للبنات ، جامعة بغداد.

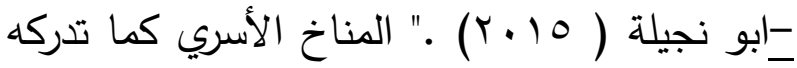
الأبناء وعلاقته بالتفكير الأخلاقي في ضوه نظهية School Students .International Journal of Advanced Research in Education \& Technology, $\operatorname{Vol}(4), \operatorname{No}(3)$.

- Ho, L., \& Et al.(2011) .Civic Disparities: Exploring Students Perceptions of Citizenship Within Singapore's Academic Tracks. Theory \& Research in Social Education, 39 )2(,203.

-Kotajoki ， J (2018) . PREVENTING VIOLENT EXTREMISM AND CRIME IN THE NORDIC COUNTRIES: SIMILARITIES, SYNERGIES AND AMBIGUITIES , SIPRI Insights on Peace and Security, Issue 3, 1-19.

-Moddry, et, al. (2007).Cognitive in the psychopathology of youth and implications for treatment, Cognitive Therapy and Research, $\operatorname{Vol}(12), \operatorname{No}(1)$.

يتقدم فريق الدراسة بالثكر لعمادة البحث العلمي ، جامعة الملك عبد العزيز - جدة، على دعمها العلمي و المادي لهذا المشروع بالمنحة البحثية رقم(-3286 


\title{
Family climate and its relationship with the tendency towards intellectual extremism and national affiliation among a female sample of students from King Abdul-Aziz University in Jeddah
}

\author{
The principal investigator, Dr. Huda Assem Mohammad khaleefah \\ Associate Professor of Mental Health, Department of Psychology \\ College of Arts and Human Sciences - King Abdulaziz University \\ Associate researcher Dr. Amira Abdul Rahman Al-Zein \\ Associate Professor of Clinical Psychology, Department of Psychology \\ Faculty of Arts and Humanities \\ King Abdulaziz University
}

\begin{abstract}
. the current study aimed to identify the relationship between the family climate and the tendency towards intellectual extremism and national affiliation among a female sample of students from King Abdul-Aziz University in Jeddah. The study included (144) female students from scientific and literary specialties. The following scales were applied :- The family climate test by Afraa Ibrahim Khalil (2006), the national affiliation scale by Ahmed Farouk Hassan (2008), and the tendency towards intellectual extremism by Muhammad Mahmoud Abu Dawaba (2012) . The most important results of the study were:there is a statistically significant relationship between the family climate and the tendency towards intellectual extremism among the sample of the study, - partial acceptance of the second assumption of the study which states that there is a statistically significant relationship between the family climate and the national affiliation,- there is an inverse relationship between the national affiliation and the tendency towards intellectual extremism. The results also showed that we can consider the family climate as an intermediate variable in the relationship between national affiliation and the tendency towards intellectual extremism, and then it can be predicted that in the absence of a family climate, negative effects of intellectual extremism may be activated , among these effects is the decrease of affiliation. The results also showed the absence of statistically significant differences between the students of theoretical colleges and the students of scientific colleges on the total score of the scales of family climate, tendency towards intellectual extremism and national affiliation.
\end{abstract}

key words: family climate - intellectual extremism - national affiliation. 